\title{
Energy-only markets and renewable energy targets: complementary policy or policy collision?
}

\author{
Tim Nelson, Cameron Reid and Judith McNeill* \\ Level 21, 101 Miller Street \\ North Sydney, NSW, 2060 \\ August 2014
}

\begin{abstract}
Australia's 20\% Renewable Energy Target (RET) was designed and implemented against a backdrop of several decades of continuous growth in electricity demand. Since the introduction of the policy in 2009 electricity demand has declined continuously. In this article, we analyse how Australia's National Electricity Market (NEM) has responded to falling demand and significant additional installed capacity as a result of climate change-related policies. We conclude that energy-only market design, barriers to exit for incumbent plant and time inconsistency of policy has resulted in investment in new renewable energy projects becoming largely intractable. In our opinion, changing the RET fixed GWh target will not alter this fact. To overcome barriers to exit, we examine three options for complementary public policy in the short-term: direct government intervention; a market-based solution; or regulation. In the long-term, a redesign of the energy-only NEM market seems inevitable.
\end{abstract}

Keywords: renewable energy; energy-only markets; barriers to exit JEL Codes: D04, D47, Q40, Q41, Q48

\section{Introduction}

Australia's electricity industry is heavily influenced by government policy. Since the commencement of the National Electricity Market (NEM) in 1998, Commonwealth and State Governments have introduced at least six material government policies designed to reduce greenhouse gas emissions or increase investment in renewable energy. These policies have profoundly altered investment decisions in an environment where electricity demand has contracted significantly, both in absolute terms and relative to historic expectation. In 2009, policy makers establishing a 20\% Renewable Energy Target (RET) expected electricity generation to increase by ca. $2.5 \%$ per annum, from $230 \mathrm{TWh}$ to about $300 \mathrm{TWh}$ in 2020 . Yet, electricity generation in 2012 was just $221 \mathrm{TWh}, 4 \%$ lower than in 2009 (esaa, 2013). Despite this, over the past decade more than $6,000 \mathrm{MW}$ of new renewable generation has been added to the NEM.

These policies have been successful in adding substantial volumes of new plant capacity. As far as we are aware, little thought was given as to how the operation of policies designed to stimulate investment in new generation capacity would operate within one of the world's most competitive energy-only gross pool electricity markets if a sustained contraction in electricity demand occurred. Policy makers and practitioners alike, ourselves included, assumed that new supply would be absorbed by increased electricity demand, while the opposite has in fact occurred. The result of declining electricity demand, along with what we describe as a newly emerging thematic of 'barriers to exit for incumbent aged thermal plant' has evidently produced intractable investment conditions. Renewable generation under current policy settings, even though it is mandated through legislation by the Commonwealth Government, is no longer financially viable.

\footnotetext{
- Tim Nelson is Head of Economics and Sustainability at AGL Energy Ltd and an Adjunct Research Fellow at the University of New England. Cameron Reid is Manager Carbon and Renewable Policy at AGL Energy Ltd. Judith McNeill is Senior Research Fellow at the University of New England. All views, errors and omissions are entirely the responsibility of the authors. Our declaration is contained in Section 9. Correspondence to tanelson@agl.com.au.
} 
Very low wholesale electricity prices and declining effective real prices from renewable energy certificates (LGCs) has resulted in total revenues falling materially below the long-run marginal cost of renewable plant entry, in spite of targets that rise sharply and require imminent commitment. Policy uncertainty almost certainly originated these effects. As Simshauser (2014) has argued, a dynamic inconsistency of the RET has induced a vicious circle. Firms expect the target to be altered, and so LGC prices have softened and investment has hence been delayed. Now such little time is left to meet the target that policy makers will almost certainly as a minimum vary the target to avoid manifest policy failure or abandon the existing policy altogether, producing a second wave of dynamic inconsistency.

Incumbent plant 'barriers to exit' are material and have in our view amplified the trends arising from dynamic inconsistency and policy uncertainty. We classify barriers to exit into four groups: 'sweating' ageing thermal plant; avoiding non-trivial site remediation costs; first-mover disadvantage; and policy uncertainty. The mean age of brown and black coal power stations is 34.2 and 27.4 years respectively and so a number of the older coal plants are well beyond design life (Simshauser and Nelson, 2012, p. 108). There are substantial costs associated with closing down a power station permanently - a cursory review of Annual Reports tends to indicate remediation costs of $\$ 100-\$ 300$ million. First-mover disadvantage costs are also material economic theory (and game theory in particular) tells us that actions taken by any one supplier to reduce capacity will make competitors better off. However, it is the final identified barrier to exit which is most likely to be present within the Australian context: policy uncertainty ${ }^{1}$.

If power stations are not decommissioned due to perceived or genuine 'barriers to exit' and are instead mothballed, the capacity remains available for dispatch albeit with advanced notice. The presence of mothballed capacity depresses expected future prices despite not physically generating electricity because the broader markets knows that capacity can, and will, be recalled above a certain price threshold. Generators may remain commissioned despite their continued availability depressing future expectations of wholesale pricing outcomes. In the short to medium term, this poses no real problem from a system security perspective. However, in the long-run reliability may ultimately be tested. Continued low wholesale electricity prices will discourage necessary maintenance expenditure on a rapidly ageing thermal generation fleet. On extremely hot days, unexpected plant outages may increase in frequency and mothballed plant will be unable to respond within the necessary timeframes. Over the long-run, this could combine to produce unintended security of supply events. In our view, policy makers need not be immediately concerned by such a scenario occurring because of the extent of oversupply. This is a long-run problem. However, we believe policy makers should begin to consider how to facilitate an 'orderly' rather than 'disorderly' exit and replacement of the ageing capital stock.

The purpose of this article is not to articulate public policy reasons for, or against, mandated renewable energy policies, nor how or at what level such targets might be set. As a means of reducing greenhouse gas emissions over the long-term, there may be sound reasons for supporting the deployment of renewable energy such as reducing long-run average technology costs over time, system portfolio and fuel mix diversification or recognising that deployment of new 'lowemission' capacity may create a capital stock that becomes redundant under a 'deep-cuts' emission reduction scenario, thereby necessitating the deployment of renewable capacity as an alternative. What we can say with confidence is that it is important for policy makers to clearly articulate why such policy is being implemented.

\footnotetext{
${ }^{1}$ There is considerable existing literature on climate change policy uncertainty in Australia (Nelson et al., 2010; Nelson et al., 2011; Simshauser and Nelson, 2012; Nelson et al., 2013).
} 
In this article we examine how climate change policies, especially mandated renewable energy targets, can co-exist with an energy-only gross pool market design in the presence of barriers to exit. This article is structured as follows: Section 2 documents a brief literature review of power generation economics against a background of declining electricity demand and mandated renewable energy supply; Section 3 outlines the results of partial equilibrium analysis of the NEM with and without new generation incentivised by government subsidies (explicit and implicit); barriers to exit are discussed in Section 4; the intractability of new investment in renewable generation is assessed in Section 5; and policy recommendations and concluding remarks are presented in Section 6 and Section 7.

\section{Power generation economics: on mandated supply and declining demand}

The NEM is classed as an energy-only gross pool electricity market in which prices are formed under a uniform first-price auction clearing mechanism. The operation of the market is well documented in Simshauser $(2006,2008,2010)$ but at its simplest, for such a market to be sustainable, it should facilitate generators recovering efficient fixed (capacity) and variable (fuel and operating) costs over the long run. Due to the highly variable nature of intra-day and seasonal electricity demand, resulting spot prices fluctuate significantly. In other industries, inventory management is used to smooth production schedules and meet variable demand. However, there are currently limited economic options for large-scale electricity storage, thus necessitating the need to match supply and demand continuously. In the Australian market, prices can (and do) increase from an average of around $\$ 30-\$ 40 / \mathrm{MWh}$ (ex-carbon tax) to $\$ 13,100 / \mathrm{MWh}$ in the space of half an hour. Prices during 'baseload' generation periods typically reflect short-run marginal costs reflecting surplus capacity available. At intermediate and peak times, spot prices rise and reflect the increasing scarcity of capacity. Extreme peak prices must be very high so that average spot prices, calculated over any extended time period, provide a revenue stream that matches total costs (both fixed and variable) of the optimal fleet of efficient generators.

In energy-only markets, generators receive payments for their energy but not their available capacity or reliability services (beyond real-time ancillary services, which represent a trivial revenue stream of less than 1\% for the average generator). Schweppe et al. (1988) first demonstrated that competitive spot electricity markets are useful constructs for matching supply and demand and providing investment signals for additional capacity requirements. Like most areas of public policy however, the real world implementation is impacted by constraints such as: the intersection of regulatory interference; financial market considerations; and market price-caps (Simshauser, 2008; Simshauser, 2010; Nelson and Simshauser, 2013; Simshauser \& Ariyaratnam, 2014; and Simshauser, 2014a). In the Australian context, one only needs to consider the proliferation of poorly coordinated and overlapping climate change policies to understand how significant regulatory interference has been (Nelson et al, 2010). Furthermore, regulators consistently attempt to artificially constrain energy prices within energy-only markets (Besser et al, 2002; Oren, 2003; de Vries, 2003; Wen et al, 2004; Finon and Pignon, 2008; Joskow, 2008; and Simshauser, 2010). The theory of energy-only markets demonstrates that prices reflect the overall cost of an efficient mix of plant, but in practice these constructs collide with real-world treatment of the financing of non-trivial sunk capital costs (Peluchon, 2003; Joskow, 2006; Finon, 2008; Simshauser, 2008; Caplan, 2012; Nelson and Simshauser, 2013; and Simshauser and Ariyaratnam, 2014) - an important point in the context of 'barriers to exit' which is discussed later in this article. 
All of these factors have ultimately led many energy economists to conclude that energy-only markets are at risk of producing inadequate revenues to support continued investment in the leastcost plant mix - also known as the 'missing money' problem (Bidwell and Henney, 2004; Neuhoff et al, 2004; de Vries, 2004; Bushnell, 2005; Roques et al, 2005; Cramton and Stoft, 2006; de Vries et al, 2008; Joskow, 2008; Simshauser, 2008; and Finon, 2008). As a result, before the introduction of very low short-run marginal cost renewable plant occurred, energy-only markets were considered by many economists to have shortcomings. Edoenhoffer et al (2013) and Caplan (2014) provide interesting insights into alternative market designs and additional mechanisms for restructured wholesale energy-only markets. It is likely that the design of the institutional structure of the NEM requires examination by policy makers. Such reform, however, will take several years to design and then several more years to affect if adopted. If policy makers wish to correct for the intractability of renewable investments identified later in this article, policy responses to overcome barriers to exit may be required sooner than one might prima facie think.

The NEM has been highly successful in facilitating plant entry as Figure 1 demonstrates. From 1997 to the time of writing, about 16,000 MW of plant capacity has been added to meet rising demand or government policy requirements. Figure 1 demonstrates that the market has responded to spot price signals. That is, as prices have increased in line with deteriorating reserve margins, market participants have invested in new capacity. As new capacity is commissioned (note the two year lag of price on the RHS y-axis), average prices fall. Figure 1 also shows that in all periods except 2007, which was affected by severe drought and plant unavailability due to shortages of cooling water, average wholesale prices have been insufficient for many plants to recover long-run marginal costs. Nelson et al (2010) noted that many large gas-fired generators commissioned after 2005 would have been bankrupted had they not been within large diversified generation portfolios.

Figure 1: Weighted-average NEM wholesale electricity prices and new investment

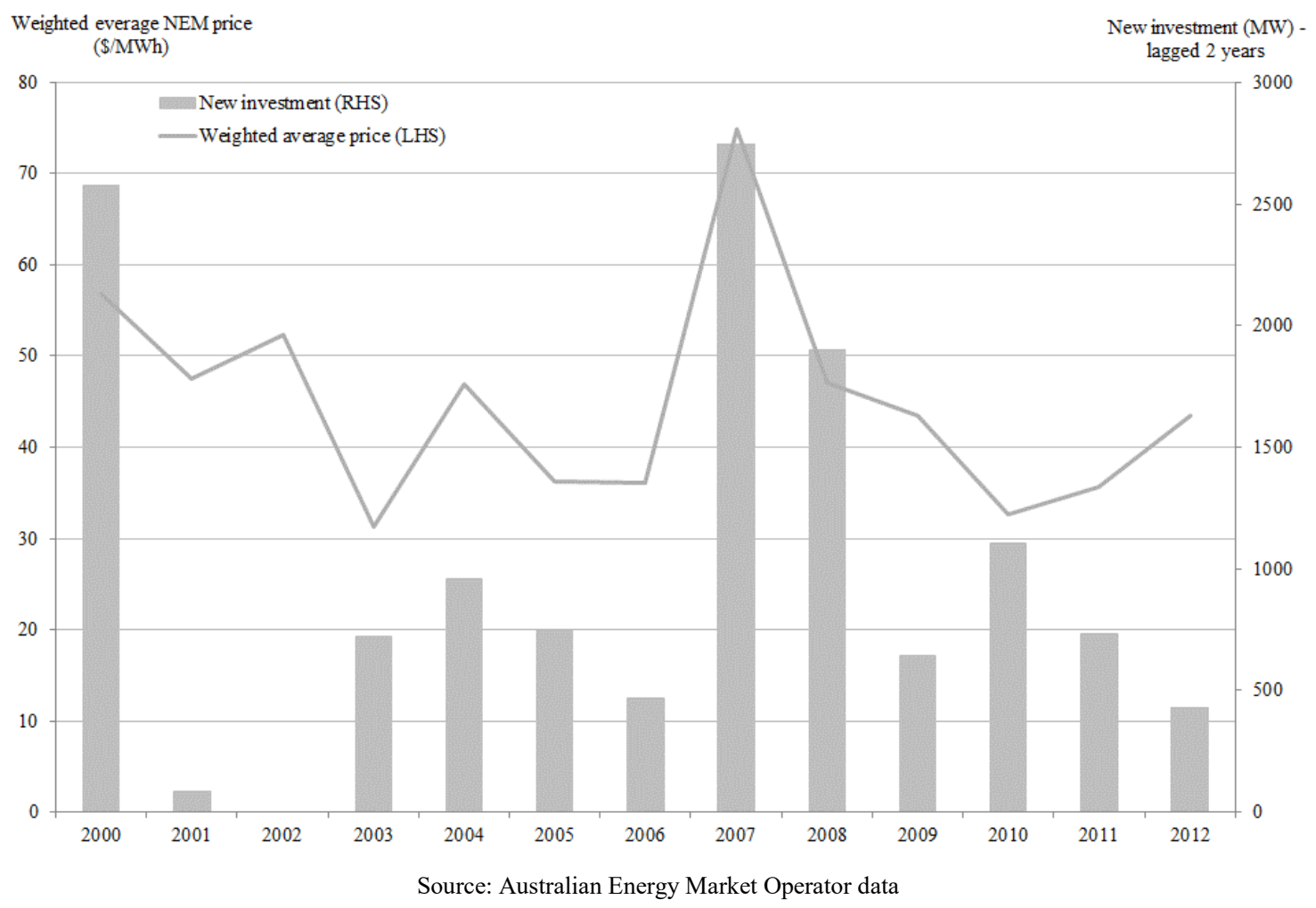


The inability to recover efficient entry costs has been accelerating and is unsurprising given recent circumstances. The shaded area of Figure 2 shows the effective reduction in capacity utilisation in the NEM due to the separation in growth of peak and underlying energy demand. Nationally, electricity demand has fallen by around 8,000 GWh since 2009, a decline of around $4.5 \%$ (Saddler, 2013, p.4). This is quite remarkable as Saddler (2013, p.4) notes:

"If electricity consumption in the NEM had continued to grow from 2005 onward at the same rate as it had for the previous twenty years, consumption would have been about 37 TWh higher in 2013 than it actually was. This difference is equal to the output of almost 5,000 megawatts (MW) of coal fired generation capacity."

Figure 2: Peak and energy demand growth

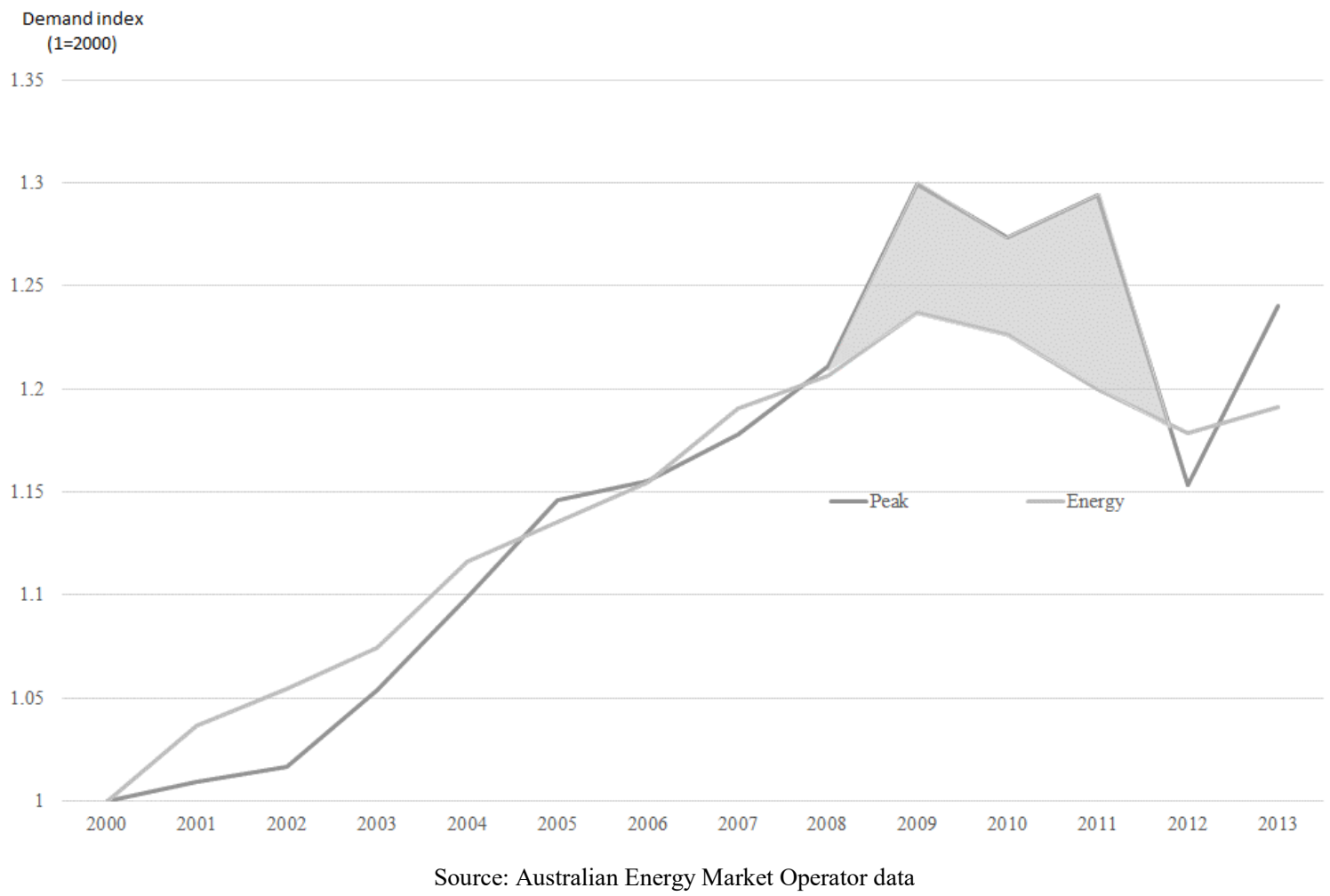

As a result of the deteriorating load factor between 2005 and 2012 and the addition of plant capacity, the utilisation rates of the NEM fleet declined from 58\% to about 50\% (Simshauser and Nelson, 2013). This has also resulted in a declining price volatility trend within the NEM as shown in Figure 3. Note that the introduction of carbon pricing in Australia in FY13 is likely to have impacted on price volatility in 2013. 
Figure 3: High pricing events in the NEM

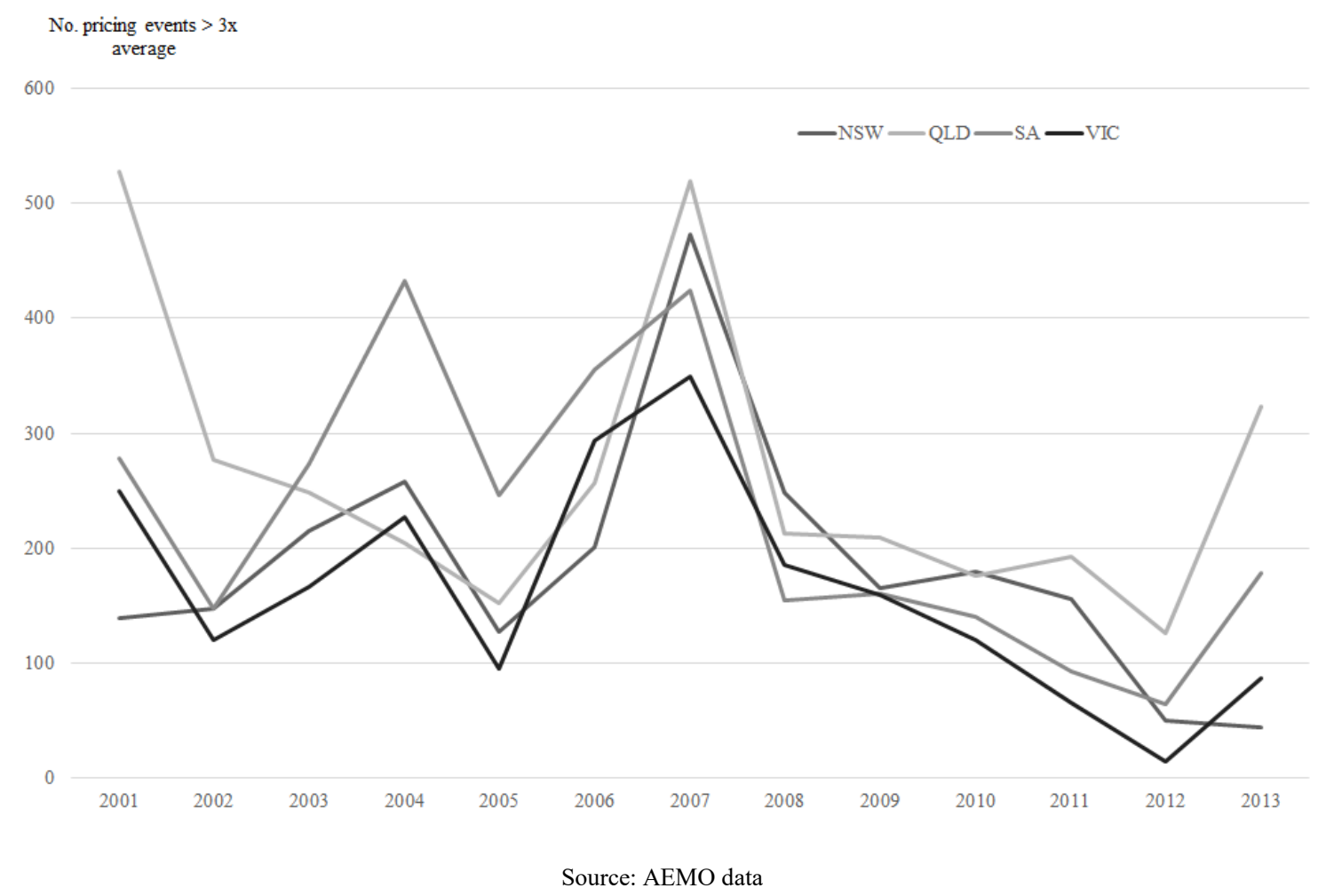

So how has resource adequacy been maintained given underlying average prices are below the LRMC of supply, and pricing volatility has declined? Simshauser (2010) noted that prior to 2007, $73 \%$ of all investments were made with the direct or indirect backing of state government-owned entities. From 2007 onwards, industrial organisation and power-purchase agreements (with investment-grade credit-rated counterparties) have been the mechanisms by which investments in large-scale generation plant have been possible (see Simshauser, 2010; Nelson and Simshauser, 2013). While this assessment is correct, it is only partially complete as Figure 6 later demonstrates (i.e. the mechanisms by which plant entry was facilitated are also important, and a majority of plant committed since 2005 has been "policy induced").

It is beyond the scope of this article to provide a definitive view on the merits of energy-only markets or alternatives such as increasing market price caps or introducing reliability mechanisms or capacity payments. But it is worth noting that estimates have been made in relation to how high the market price cap would need to be increased for generators to recover their long-run costs - Simshauser (2008) concluded an increase from $\$ 10,000$ to $\$ 24,500 / \mathrm{MWh}$ prior to the RET, whereas Riesz (2014) concluded an increase from $\$ 13,100$ per MWh to around $\$ 30,000$ per MWh after accounting for the RET. If the NEM moved to being supplied by $100 \%$ renewable energy, Riesz (2014) estimates that the the cap would need to increase to between $\$ 60,000$ and $\$ 80,000$ per MWh. 
Given existing price caps and floors, it is worth exploring how the NEM's institutional design may influence the operation of the RET policy in an environment of declining or stagnant electricity demand. In Figure 4, we have constructed the scenario envisaged by policy makers when the RET was first legislated. The addition of very low short-run marginal cost renewable plant shifts the supply curve from $S_{1}$ to $S_{2}$. At the same time, demand growth results in the demand curve shifting from $\mathrm{D}_{1}$ to $\mathrm{D}_{2}$. For simplicity, we have presented only one demand point although in reality there are 17,520 final demand points representing each half hour in a year. The increase in both supply and demand results in prices being maintained at $\mathrm{P}_{1}=\mathrm{P}_{3}$. The dominant thinking at the time of the introduction of the policy was that increased supply due to renewable energy proliferation would be absorbed by increased demand, negating any material impacts on the electricity market.

Figure 4: Stylised analysis of an increase in demand and increase in supply

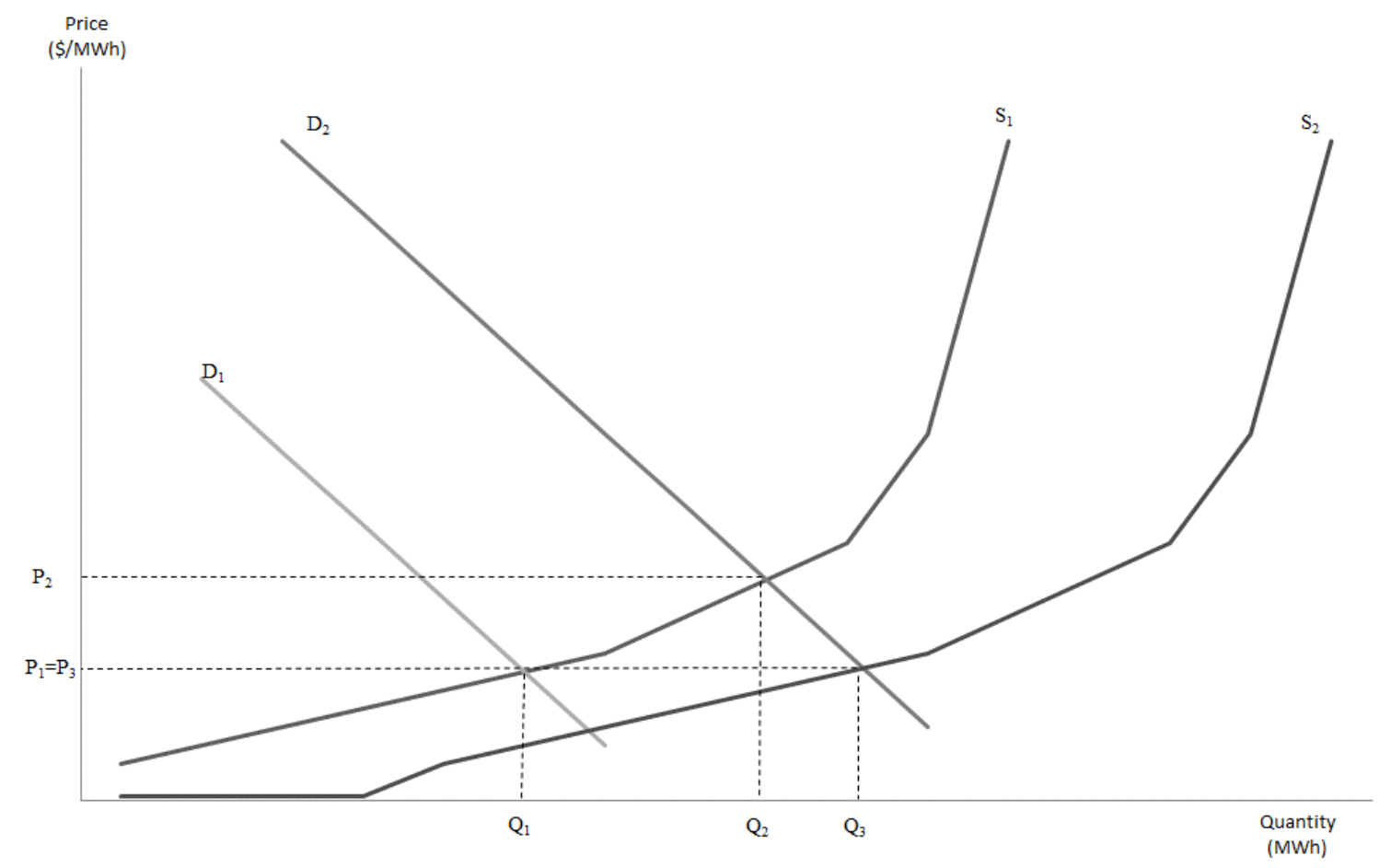

Since the introduction of the $20 \%$ RET in 2009 however, electricity demand has fallen by $4 \%{ }^{2}$. To demonstrate how this can materially impact the economics of power generation in the NEM, we have reconstructed our static analysis to show the same increase in supply but with a decrease in electricity demand. This is shown in Figure 5.

\footnotetext{
${ }^{2}$ Within the existing economics literature, little has been written about the consequences of the lack of integrated energy market reform across wholesale markets, transmission and distribution and retail tariff design. It could be argued that Australian electricity generators in deregulated wholesale markets have been 'economic passengers' through poor policy decisions relating to the $70 \%$ of the final retail tariff that is unrelated to wholesale markets (distribution and retail tariffs). Retail prices have increased substantially in recent years (see Simshauser, Nelson and Doan, 2011) due to lower capacity utilisation driven by the lack of cost-reflective retail tariffs and price regulation. Resulting reductions in electricity demand are beyond the influence of electricity generators creating a 'slow-burn' crisis whereby reduced capacity utilisation reduces the incentive for maintenance spending. This may manifest in time through poorer generation reliability. An examination of these issues is worthy of further research.
} 
Figure 5: Stylised analysis of an increase in supply and decrease in demand

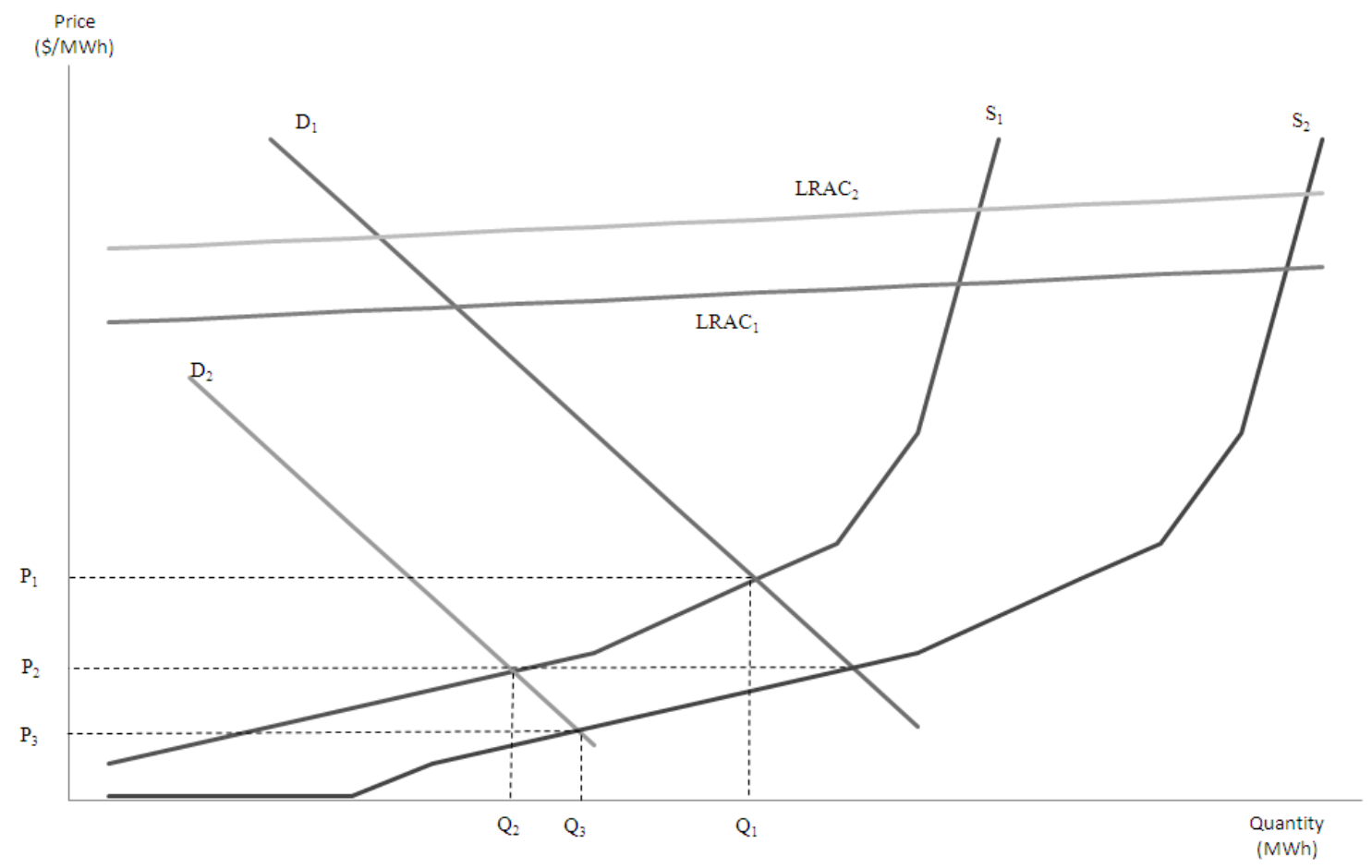

As demand falls from $D_{1}$ to $D_{2}$, wholesale prices fall from $P_{1}$ to $P_{2}$. At the same time, additional investment in very low short-run marginal cost renewable plant shifts the supply curve from $S_{1}$ to $\mathrm{S}_{2}$. This engineered oversupply through the use of consumer-funded subsidies results in (the nonsubsidised or underlying) wholesale price falling further to $\mathrm{P}_{3}$, something we observed in relation to the NEM in practice earlier in this article. To contrast costs and prices, the increase in the longrun average cost (LRAC) of generation is shown as a shift of the curve from LRAC 1 to $\mathrm{LRAC}_{2}$. A reduction in prices due to engineered oversupply and contracting demand has two main consequences. First, wholesale price reductions manifest themselves as prima facie savings to consumers (known in the literature as the 'merit-order effect'). And second, a greater proportion of revenues for new renewable investments must come from subsidies to ensure the increase in long-run average cost (LRAC) is funded - in the case of the 20\% Renewable Energy Target revenue from LGCs must increase, resulting in rising retail prices. Ultimately, a renewable energy investment, ceteris paribus, would be expected to recover long-run marginal cost over its economic life for investment to continue to be forthcoming. In the case of Australia's NEM, a reduction in wholesale market revenue in the form of lower prices must necessitate an increase in LGC revenue and consumer prices.

Much has been made of the 'benefits' associated with lower wholesale prices due to the introduction of renewable capacity - identified in the literature as the 'merit-order effect' (see for example Sensfuß et al, 2008). Theoretical analysis suggests the 'merit-order effect' is neither welfare enhancing nor likely to hold in the long run (Felder, 2011; Nelson, Simshauser and Nelson, 2012; and Edoenhoffer et al, 2013). Above all, adding substantial volumes of high cost plant (even with low to zero marginal running costs) cannot, by definition, lead to lower long-run retail electricity prices if the cost of generation is higher than that of the incumbent fleet. Of course, in the short-run, deliberately engineering an oversupply of any kind of technology will almost certainly result in reduced wholesale prices holding all else (including thermal plant reaction functions) constant. However, this is a wealth transfer, not an increase in welfare. In particular, the largest wealth transfer is from existing producers, including incumbent renewable generators, to consumers and fails to anticipate longer term implications (i.e. on investor 
confidence, on generator gaming and so on). Felder (2011, p. 34) sums up this apparent economic contradiction succinctly,
$\therefore$..if all electricity was provided by out-of-market technologies wholesale energy prices would be near zero, yet consumer electricity costs would increase to cover the additional costs of these technologies, thereby indicating that there was something amiss.'

In other words, any 'merit-order effect' must be transitory in nature. In the long-run, higher average cost generation technologies must result in higher costs to society than lower average cost generation technologies.

The second identified consequence of increased renewable supply with declining demand relates to the level of subsidies required to fund the increase in long-run average cost. This is something that we will explore in greater detail in Section 5 when considering the 'intractability' of new investment in renewable energy in Australia given current policy settings. Edenhofer et al (2013, p. 519) provide an excellent discussion of the interaction of renewable energy investment and 'missing money' in energy-only markets. Their conclusion is that:

'lower average prices caused by higher renewable energy penetration lead to a reduction of overall capacity, which in turn increases the frequency of scarcity events and respective scarcity prices. According to theory this will bring the market back to the long-term equilibrium in which long-run average costs and average revenues are balanced for all capacities and where, as a direct result, the capacity level is efficient.'

A critical assumption for this conclusion to be valid is that incumbent inflexible thermal power stations retire permanently from the market, and are decommissioned. However, the literature largely ignores the presence of 'barriers to exit'. Riesz, Noone and MacGill (2013, p. 15) highlight that several coal-fired generation units have been mothballed or withdrawn for seasonal operation in Australia's NEM. If power stations are not decommissioned, their capacity remains available for dispatch with advanced notice. The presence of mothballed plant capacity depresses expected future prices despite not physically generating electricity because it can be recalled with notice. If economic barriers to exit exist for surplus plant, generators may remain commissioned despite their continued availability depressing future expectations of wholesale pricing outcomes. The Australian experience is discussed in the subsequent section of this article. ${ }^{3}$

\section{Optimal Plant Mix of Australia's NEM - declining demand and increased supply}

Since 1998, a number of policies have been introduced to provide economic incentives to invest in various types of new generation irrespective of whether the supply/demand balance of energy within the NEM deemed such investment necessary. These include: (1) the Mandatory Renewable Energy Target; (2) the Large Scale Renewable Energy Target; (3) Premium Feed-in Tariffs (FiT) for embedded generation; (4) the NSW Greenhouse Gas Abatement Scheme; (5) the Clean Energy Act (carbon pricing); and (6) the 13\% (subsequently 18\%) Queensland Gas-fired Electricity Generation Scheme. There have also been various capital subsidies for solar hot water and embedded solar PV generation units (i.e. overlapping policy). Nelson et al (2010) provide an

\footnotetext{
${ }^{3}$ At the time of writing, there is significant focus on the Magritte Group which is a lobby group of 10 of the largest European utilities (see Lewis, 2014). The Group has advocated for the removal of renewable subsidies with decarbonisation to be achieved through a carbon price. A key difference between the European and Australian markets is the widespread acceptance in Europe of carbon pricing. Significant carbon policy uncertainty prevails in the Australian market (see Nelson et al, 2012).
} 
overview of the various types of climate change and renewable energy policies which have been introduced over the preceding two decades which we do not intend to replicate here.

Figure 6 shows that investment in the NEM can be broken into two temporal components. First, between 1997 and 2002 a range of merchant investments were made for the purposes of meeting increasing electricity demand (Simshauser, 2010). None of these investments received a capital subsidy or ongoing support in the form of certificated-based revenue streams. However, from 2003 onwards almost all investment in new generation has been supported by either capital subsidies or revenue support from certificated schemes. In fact, cumulative new lower emission investment in electricity generation totals around 10,000 MW since the commencement of the NEM. Under normal conditions, the impacts of policy-induced new capacity would be trivial due to expanding demand. However, as we noted earlier, demand is contracting and this raises certain problems.

Figure 6: New plant investment by incentive type

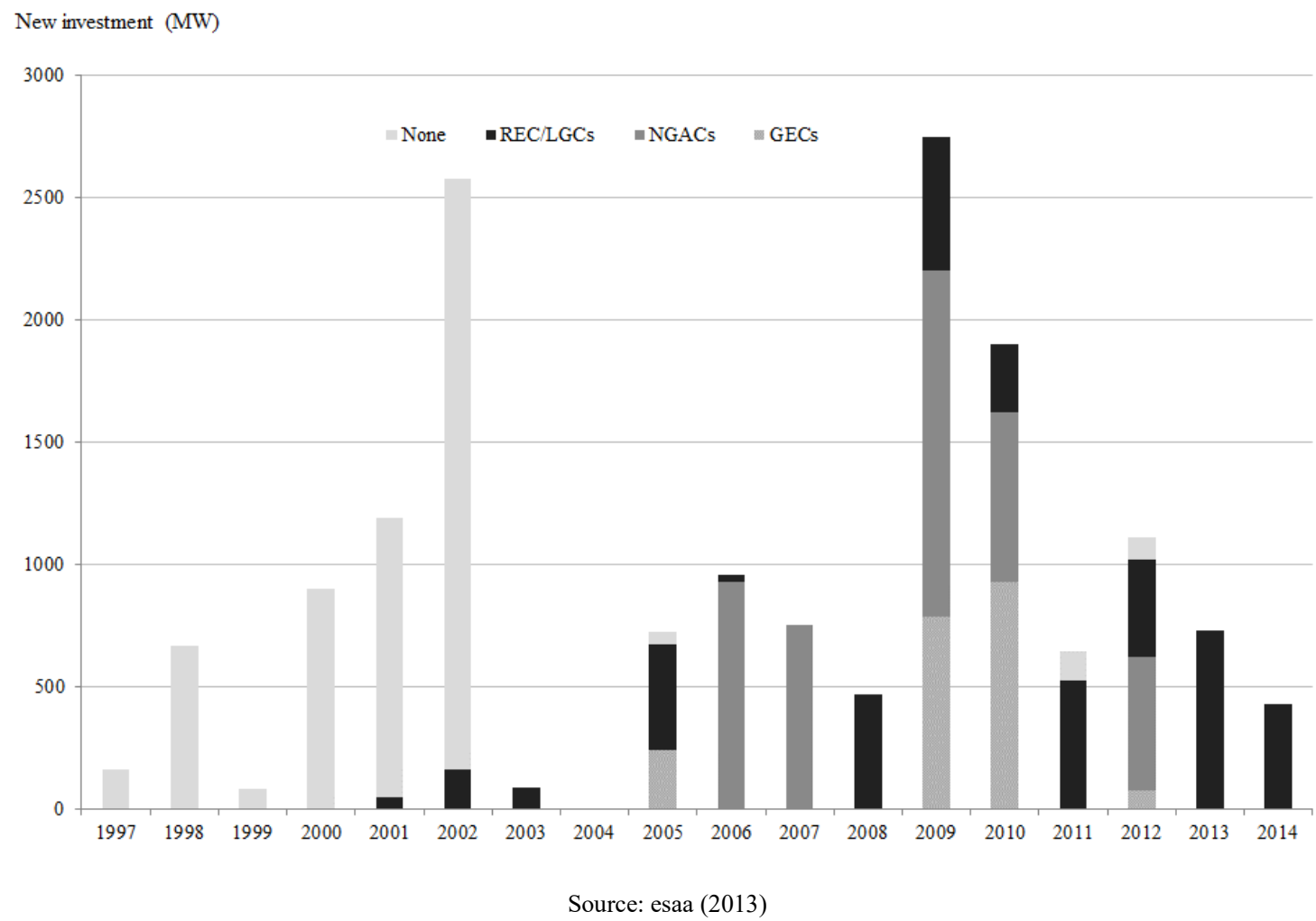

Investments in low-emission and renewable plant in response to various policy subsidies has had the desired effect in relation to greenhouse gas emissions reductions in the electricity sector. In the years between 1990 and 2007, greenhouse gas emissions from the electricity sector increased by 75 million tonnes (mt) (DIICCSRTE, 2013). Since 2007, emissions have fallen by $25 \mathrm{mt}$, driven by declining electricity demand and the introduction of low emission generation capacity. This is shown in Figure 7 which illustrates the cumulative investment in low-emission (gas) and renewable generation since 2003 (LHS) and the emissions intensity of electricity supply (RHS). As new generation capacity has been added to the electricity system, and as demand for electricity has coincidentally declined, the emissions intensity of electricity supply has declined by approximately $15 \%$, from ca. $0.95 \mathrm{t} / \mathrm{MWh}$ to around $0.8 \mathrm{t} / \mathrm{MWh}$. 


\section{Figure 7: Cumulative low emissions investment and emissions intensity}

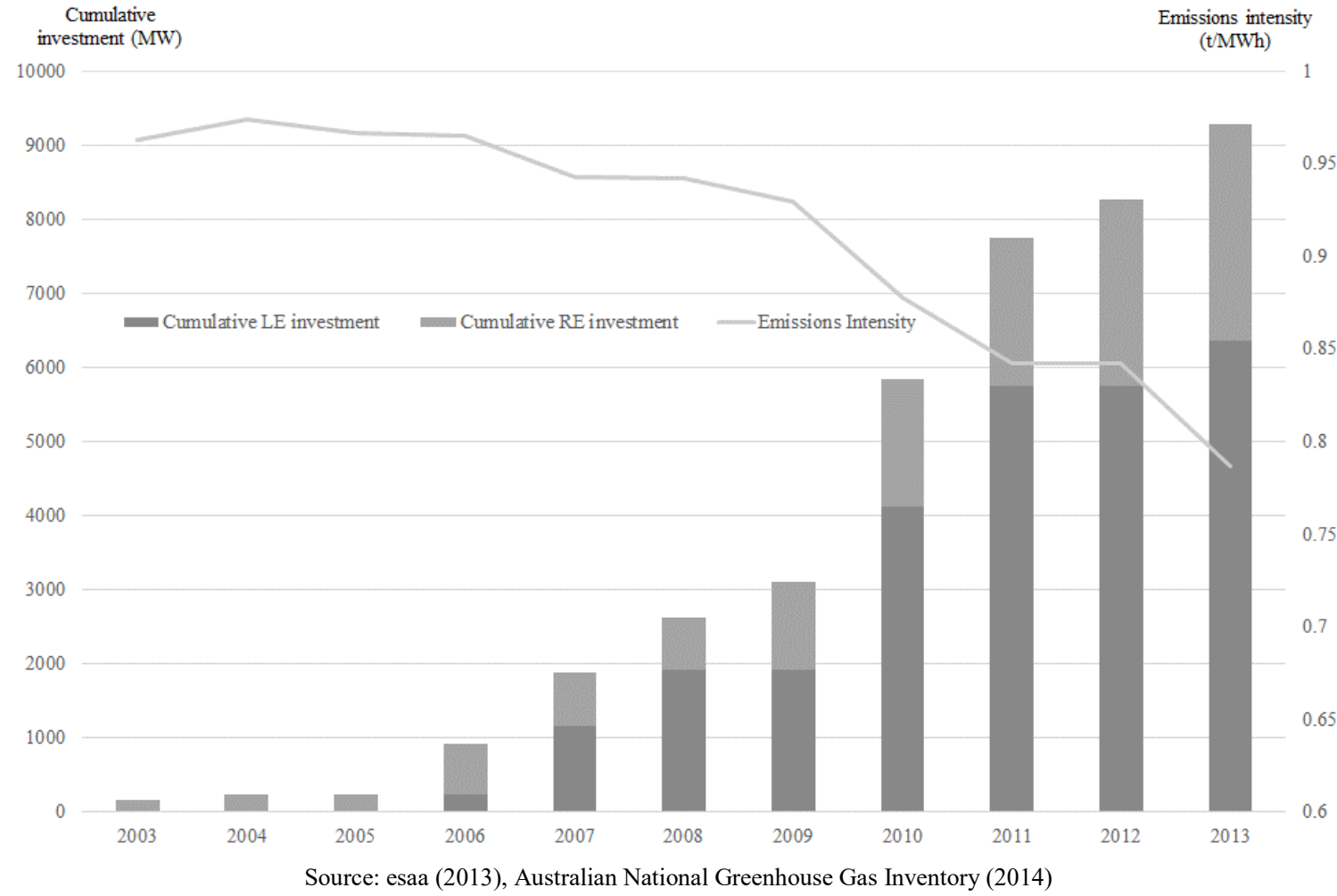

Figure 8: Capacity factor of steam plant and cumulative RE capacity installed

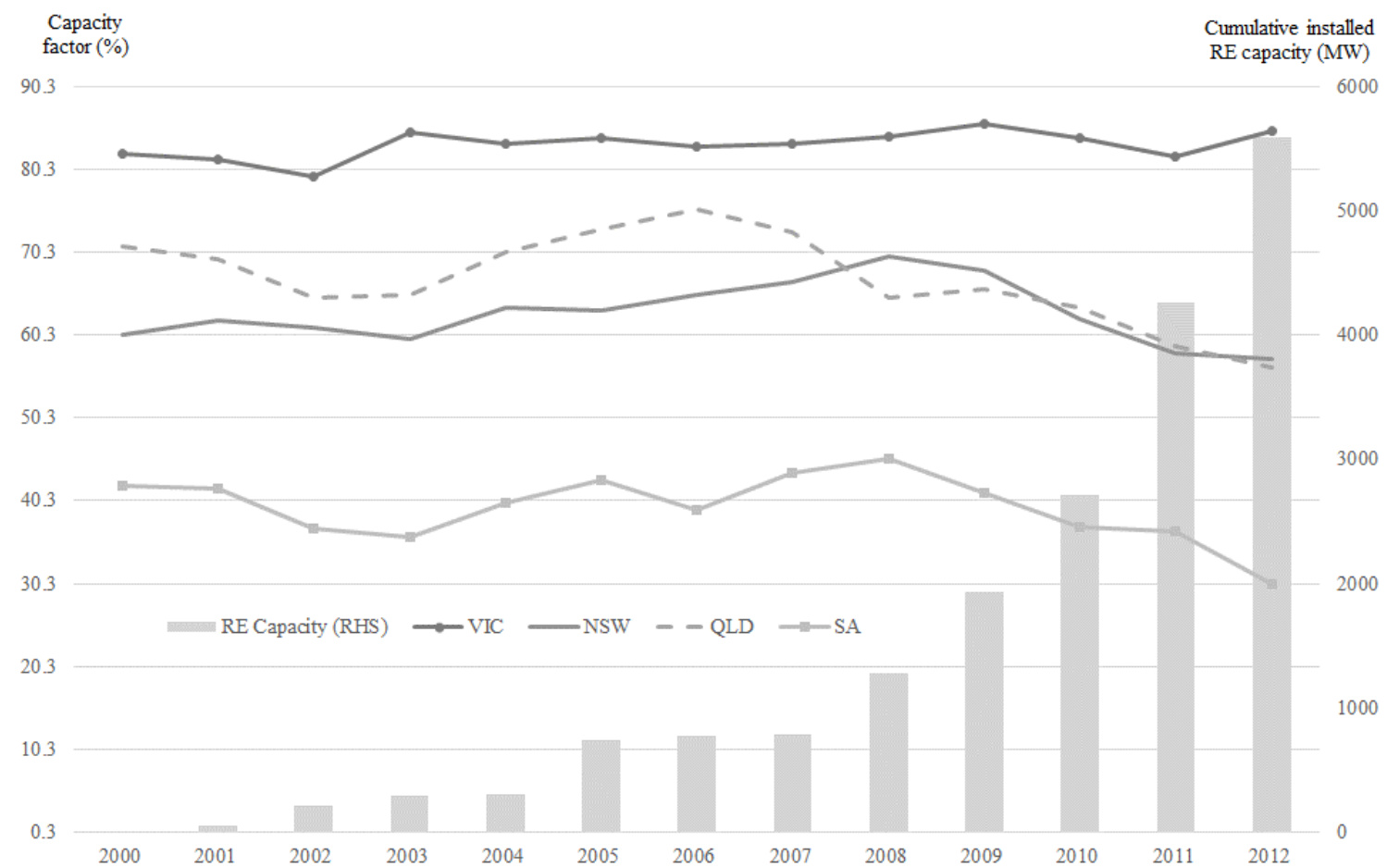

Source: esaa (2013)

Steam plant capacity factors have fallen sharply in all regions except Victoria (which ironically, has the highest emissions intensity). Figure 8 shows that the capacity factors of incumbent thermal plants in Queensland, South Australia and New South Wales have declined materially 
since 2008. This is an important observation because it highlights that while energy output from incumbent power stations has declined, capacity has remained available for dispatch. In other words, while theory might indicate permanent plant retirements, this has not occurred - at least at the level one might expect. Market participants are able to mothball plant at relatively low cost by comparison to the very high capital cost of retirement. And this is amplified given the option value associated with the plant's potential to return to service with notice of only a few months. Beyond the misallocation of scarce capital, this outcome has had an adverse impact on the NEM's plant mix by comparison to a welfare maximising, optimal (least cost) plant mix.

To analyse the impacts of climate change policies on the optimal plant mix within the NEM, two scenarios have been modelled using a partial equilibrium model ${ }^{4}$ :

- $\quad$ Scenario 1: An optimal plant mix is derived for the FY14 load curve. This optimal plant mix is then contrasted with the existing supply (by plant type). Renewable generation is not characterised as baseload, intermediate or peaking but is instead deducted from final demand to form a 'residual load curve' in a manner consistent with Bushnell (2010) and Simshauser (2011).

- $\quad$ Scenario 2: The same optimal plant mix is derived for FY14. However, existing supply is adjusted to remove all plant that has received some form of government subsidy (identified in Section 3). As in scenario 1, renewable generation is absorbed using the methodology outlined in Bushnell (2010) and Simshauser (2011).

The assumptions for current power station fixed and variable costs are sourced from Simshauser and Ariyaratnam (2014) and are presented in Figure 9.

\section{Figure 9: Power station fixed and variable costs by different technology}

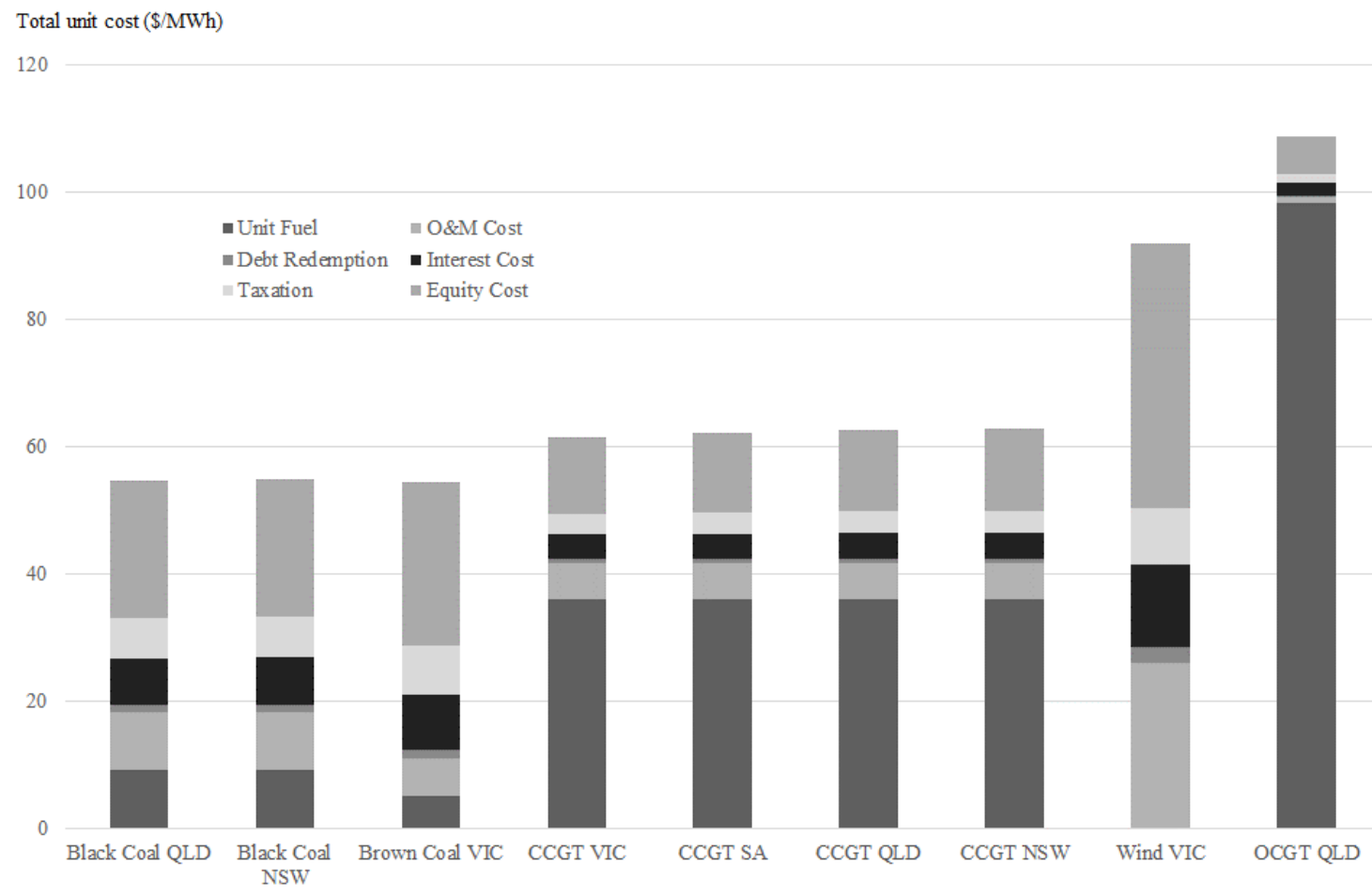

Source: Simshauser and Ariyaratnam (2014)

\footnotetext{
${ }^{4}$ Our optimal plant mix model is based upon Berrie (1967). The model is consistent with that outlined in Simshauser \& Wild (2009) and so we propose not to reproduce it here.
} 
Figure 10: Optimal plant mix results for coal, CCGT and OCGT technologies

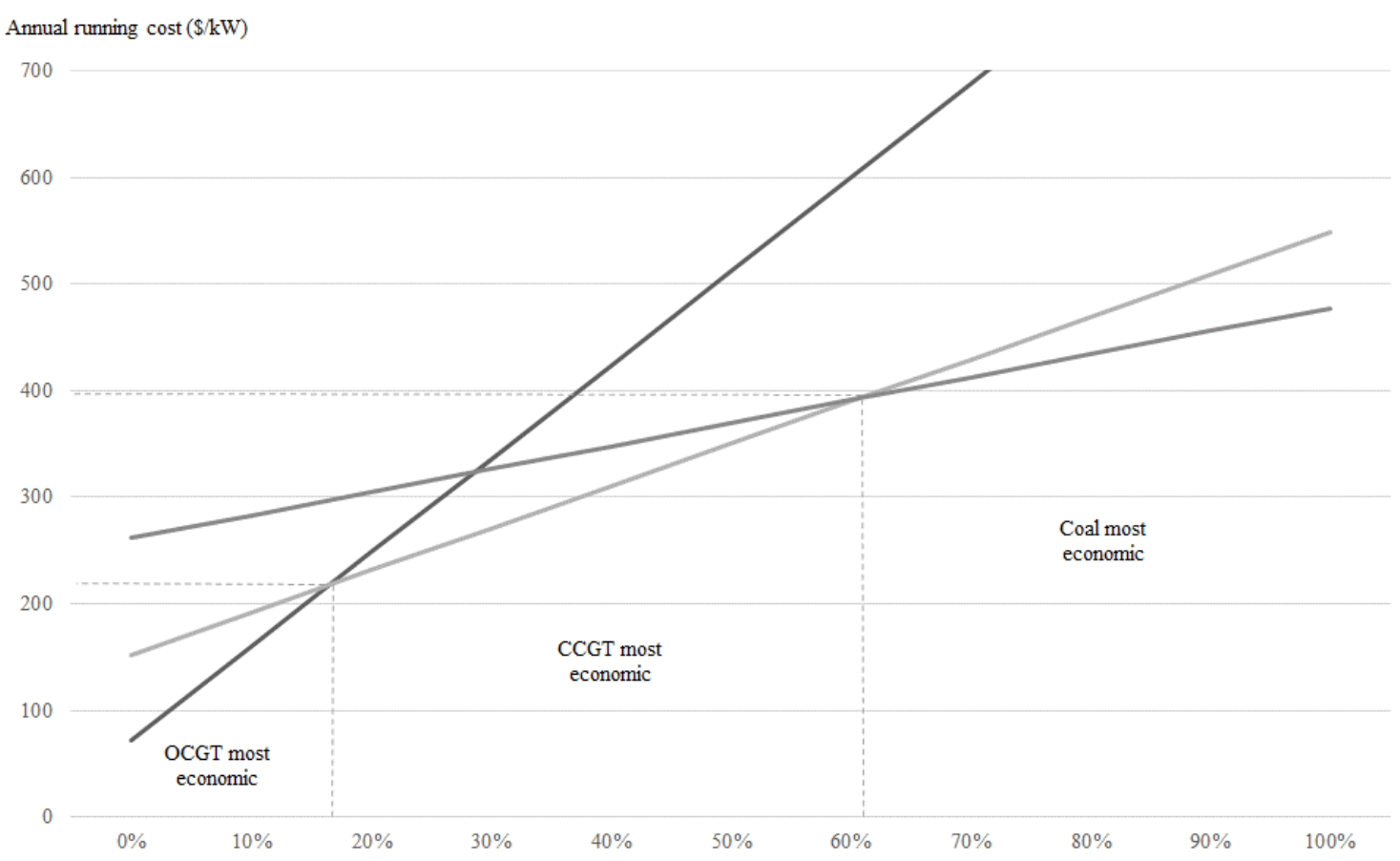

Electricity load (MW)

40,000

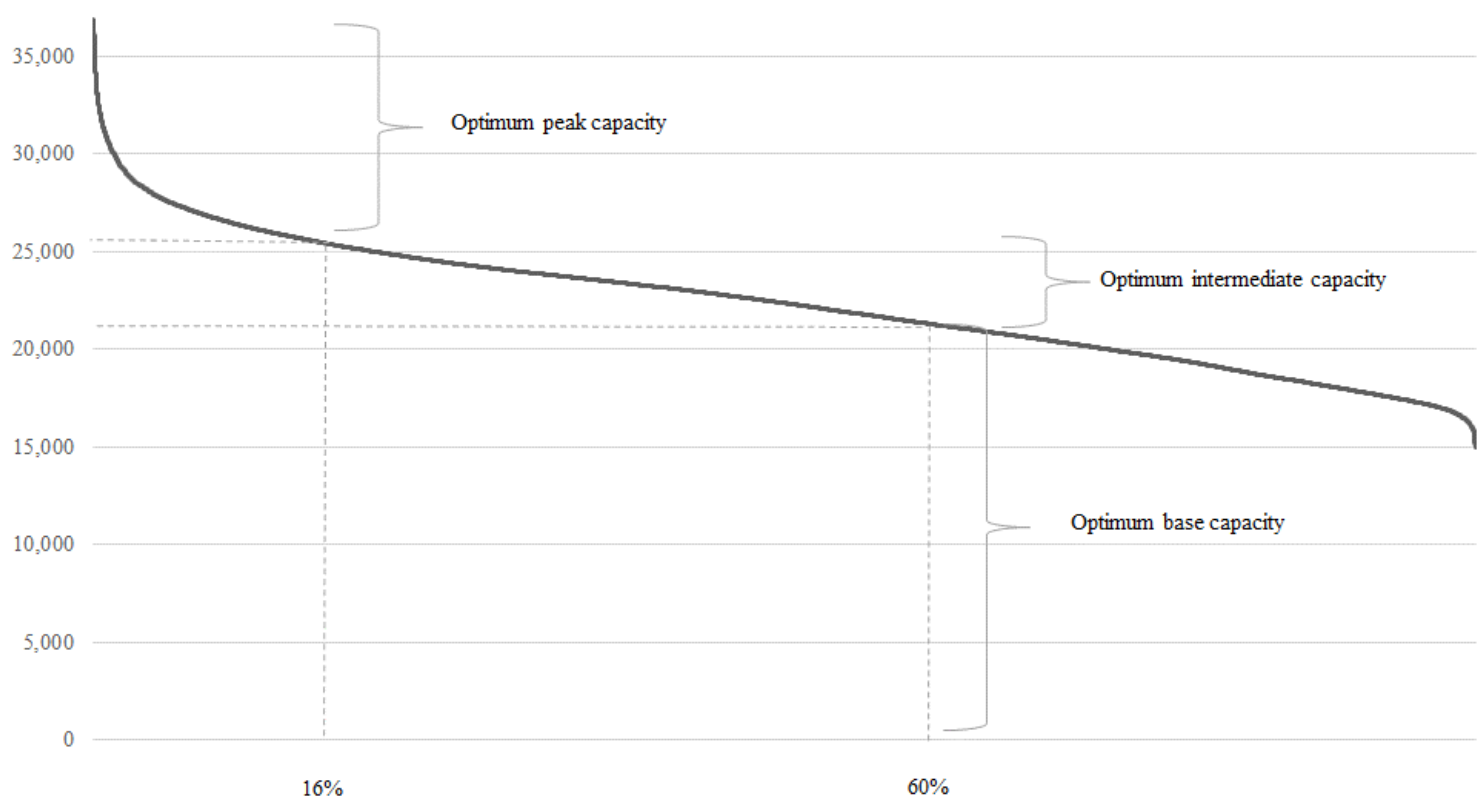

The results of the optimal plant mix calculations are presented in Figure 10. Utilising the FY14 NEM load duration curve, and assuming new technology economics from Figure 9, the optimal plant mix is approximately $14 \mathrm{GW}, 4 \mathrm{GW}$ and $20 \mathrm{GW}$ of peaking, intermediate and baseload plant, respectively. 
Table 1 contrasts the FY14 optimal plant mix results with the actual installed generation mix in 2013/14. Base and intermediate-load technology categories are around 7,300 MW overweight while peaking plant is underweight by around $500 \mathrm{MW}$. Overall, the market is ca.7,000 MW oversupplied.

Table 1: Optimal plant mix results adjusted for renewables (Scenario 1) ${ }^{5}$

\begin{tabular}{ccccc}
\hline Plant Type & Optimal Mix & $\begin{array}{c}\text { Actual Mix } \\
\text { (FY14) }\end{array}$ & Imbalance & Weighting \\
\hline Baseload & 19,800 & 25,100 & 5,300 & overweight \\
Intermediate & 3,700 & 5,700 & 2,000 & overweight \\
Peaking & 14,200 & 13,700 & -500 & underweight \\
Renewable & 2,800 & 3,000 & 200 & overweight \\
\hline Total & 40,500 & 47,600 & 7,100 & oversupply \\
\hline
\end{tabular}

The results from Scenario 2 are presented in Table 2. Recall that in this scenario all policyinduced plant is essentially removed from the plant stock. It is interesting to note that the removal of this capacity results in the overall market being almost balanced. However, the suboptimal investment structure remains - with an oversupply of baseplant and an undersupply of peaking plant. It is important to note that the consequences of sub-optimal supply are not purely a function of the overall state of demand and supply. The consequences are also a function of the sub-optimal mix. In the case of the NEM, some existing base plants are operating with intermediate duties and sharply reduced capacity factors compared to original plant design. Policy makers should be concerned that there is little discussion about why such a suboptimal mix persists when aged plant could be retired.

Table 2: Optimal plant mix results - subsidy driven plant excluded (Scenario 2)

\begin{tabular}{ccccc}
\hline Plant Type & Optimal Mix & $\begin{array}{c}\text { Actual Mix } \\
\text { (FY14) }\end{array}$ & Imbalance & Weighting \\
\hline Baseload & 20,800 & 23,500 & 2,700 & overweight \\
Intermediate & 3,700 & 3,900 & 200 & overweight \\
Peaking & 14,300 & 11,400 & $-2,900$ & underweight \\
Total & 38,700 & 38,800 & 100 & oversupply \\
\hline
\end{tabular}

Figure 11 provides the practical outworking of excess supply, contracting demand and the significant addition of renewable and low-emission capacity. It displays the material reduction in the utilisation of steam plant. Capacity utilisation of the entire system has reduced materially, undoing much of the gains achieved through the Hilmer microeconomic reforms of the $1990 \mathrm{~s}^{6}$.

\footnotetext{
${ }^{5}$ Figures do not add precisely due to rounding in both Table 1 and Table 2.

${ }^{6}$ The Australian gas market is also undergoing significant change. Simshauser and Nelson (2014) forecast that gas-fired generation is likely to become uneconomic due to steeply rising gas prices. However, it is expected that the capacity will remain in the market for 'extreme peaking duties'.
} 
Figure 11: System capacity utilisation and new investment

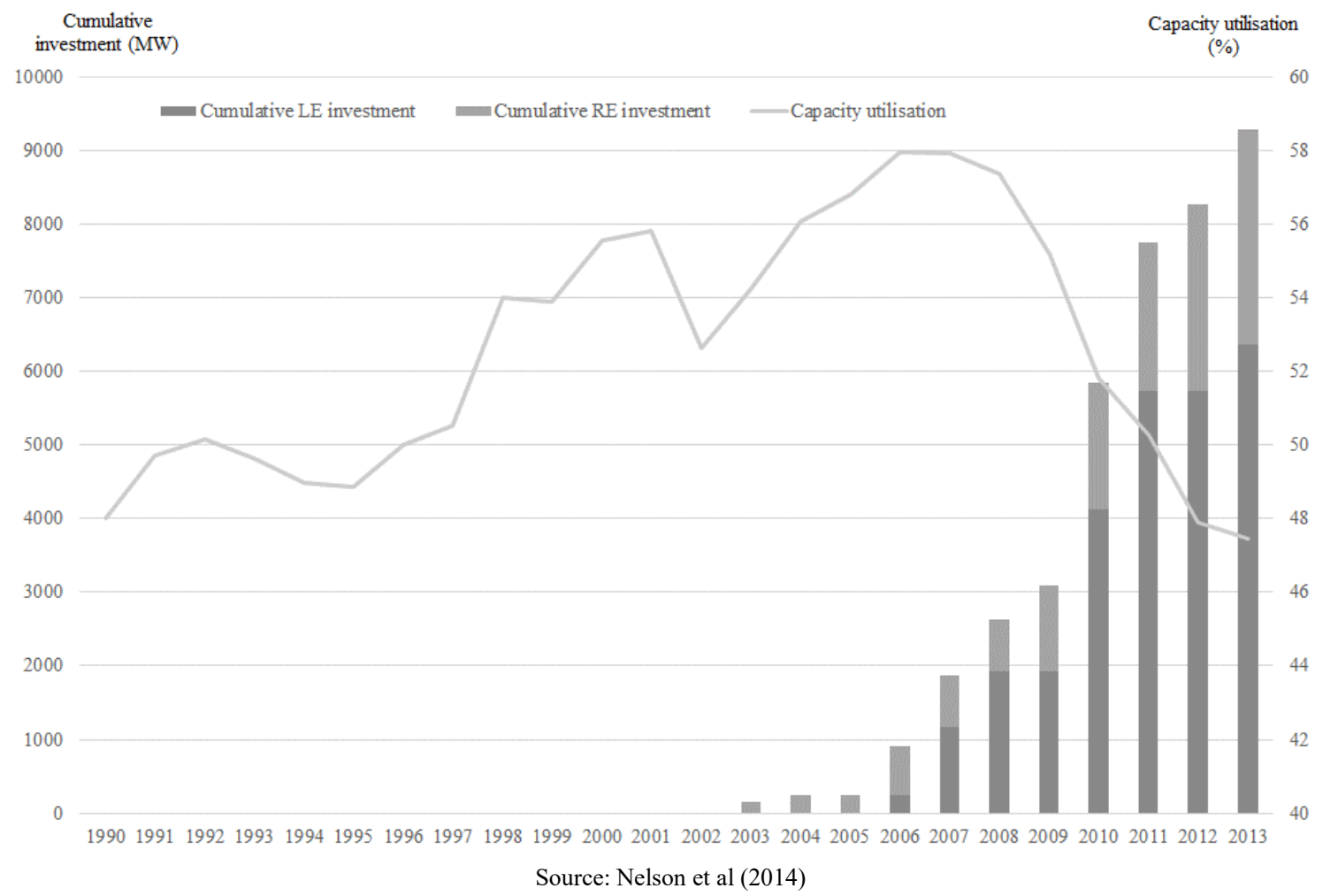

Our results show that the current mix of plant within the NEM is sub-optimal, capacity factors are plunging, and by implication the thermal efficiency and overall productivity of the power station fleet must be declining. A critical question for policy makers is whether this will persist, or whether action might be taken by market participants through plant retirements to correct these material imbalances. Growth in underlying energy demand would seem unlikely in the short term, and a corresponding rebalance of capacity away from overweight base plant to underweight peaking equipment just as unlikely as a result. Therefore our focus must turn to why market participants have not retired plant which has long since passed its technical design life.

\section{Barriers to exit}

Are barriers to exit preventing optimal retirement and new investment decision making? As outlined earlier, we have identified four barriers to exit that may be preventing efficient outcomes. Firstly, market participants with aged plant carry very low economic costs (i.e. sunk costs) and so are likely to 'sweat' assets until the marginal cost of operations and maintenance exceeds revenues obtained from reduced operating duties. This is rational behaviour for the firm, but given environmental policy objectives is suboptimal from a whole-of-system perspective. Assuming a design life for thermal plant is $25-30$ years, ca. $75 \%$ of the existing thermal plant has passed its useful life. More importantly, ca. $20 \%$ is more than 40 years old (CPCU, 2014) ${ }^{7}$.

Secondly, participants have a disincentive to exit due to "first-mover disadvantage". Given the relatively narrow variance of short-run marginal costs and emissions intensities of existing coalfired power stations, participants are reluctant to 'blink first' and make competitors economically better off by permanently retiring plant.

\footnotetext{
${ }^{7}$ We expect that these generators will continue to operate at reduced loads until expected future revenues are less than expected future costs.
} 
Third, a major barrier to exit is avoidance of site remediation costs. Ongoing mothballing of plant, rather than permanent retirement, is evidently a preferred option as site remediation costs are postponed ${ }^{8}$. Importantly however, mothballing does not correct the optimal supply mix or overall oversupply because the plant can be recalled to service within relatively short timeframes.

Fourth, and we suspect most significantly, is the barrier caused by ongoing policy uncertainty, and the dynamic inconsistency of policy. Nelson et al (2010), Nelson et al (2011), Simshauser and Nelson (2012) and Nelson et al (2013) demonstrated the significant impacts on the electricity sector arising from ongoing public policy uncertainty in relation to climate change and renewables. In particular, Nelson et al (2010) demonstrated that policy uncertainty was producing sub-optimal investment incentives vis-à-vis generation equipment. It is not difficult to envisage that the same uncertainty leading to sub-optimal decision making vis-à-vis plant maintenance and retirement. Policy uncertainty would appear to be more problematic for Australian energy market participants at the time of writing because there is an absence of bipartisan support for virtually all aspects of climate change policy.

The Australian electricity sector may now be entering a 'vicious cycle' of rational and sequential adaptive expectations. A history of (continuous) change to climate change-related energy policies has led to a collapse in policy confidence. It could be argued that the very uncertainty the industry is concerned about has been created by the industry itself, in an effort to address the effects of prior policy uncertainty events. This explains vocal statements made by the electricity supply industry during the Climate Change Authority Review of the Renewable Energy Target in 2012 (CCA, 2012).

The conditions which prompted many Australian utilities to question the RET in 2012 have become worse, not better. Electricity demand contraction has been more persistent than initially thought, and aged power stations have failed to exit. Nelson et al (2013) found that policy uncertainty was resulting in sub-optimal pricing of LGCs, with the then price being \$36 per certificate. LGC prices at the time of writing are just $\$ 25$ per certificate. The market appears to be pricing-in a manifest reduction in the RET target. Given this history, it is questionable in our view as to whether credible policy settings are at all achievable in relation to the RET.

Irrespective of why aged generators have not permanently closed, the impact on the wholesale market arising from new renewable plant, limited exit and demand contraction is acute. Figures 12 and 13 present the aggregate supply curves in the NEM in 1998 at market start and in 2014 respectively. The entire supply curve has shifted to the right - and capacity installed far exceeds requirements. When considered against the backdrop of power station economic theory presented in Section 2, it seems clear that the addition of dramatically more low-SRMC plant (on the left of Figure 13) will have the effect of reducing wholesale electricity prices, holding all else constant. In fact, forward electricity prices in some NEM regions at the time of writing are at historically low levels (see Appendix 1).

\footnotetext{
${ }^{8}$ A recent submission by an environment organisation suggested remediation costs for one power station in Victoria could be as high as $\$ 483$ million (http://environmentvictoria.org.au/newsite/sites/default/files/useruploads/EV\%20Submission_FINALR.pdf) 
Figure 12: Aggregate supply curve at market start (1998)

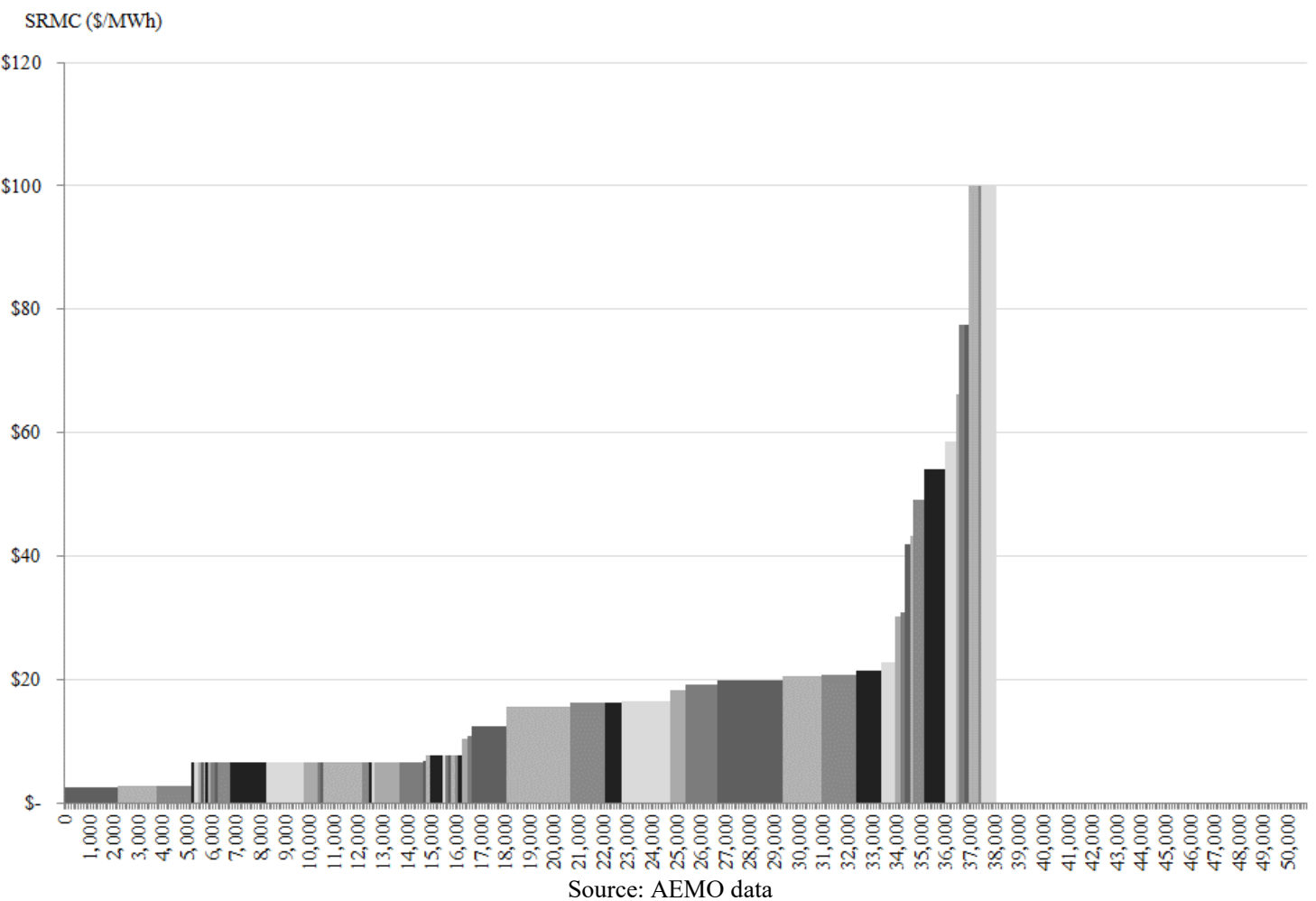

Figure 13: Aggregate supply curve (2014)

$\operatorname{SRMC}(\$ / M W h)$

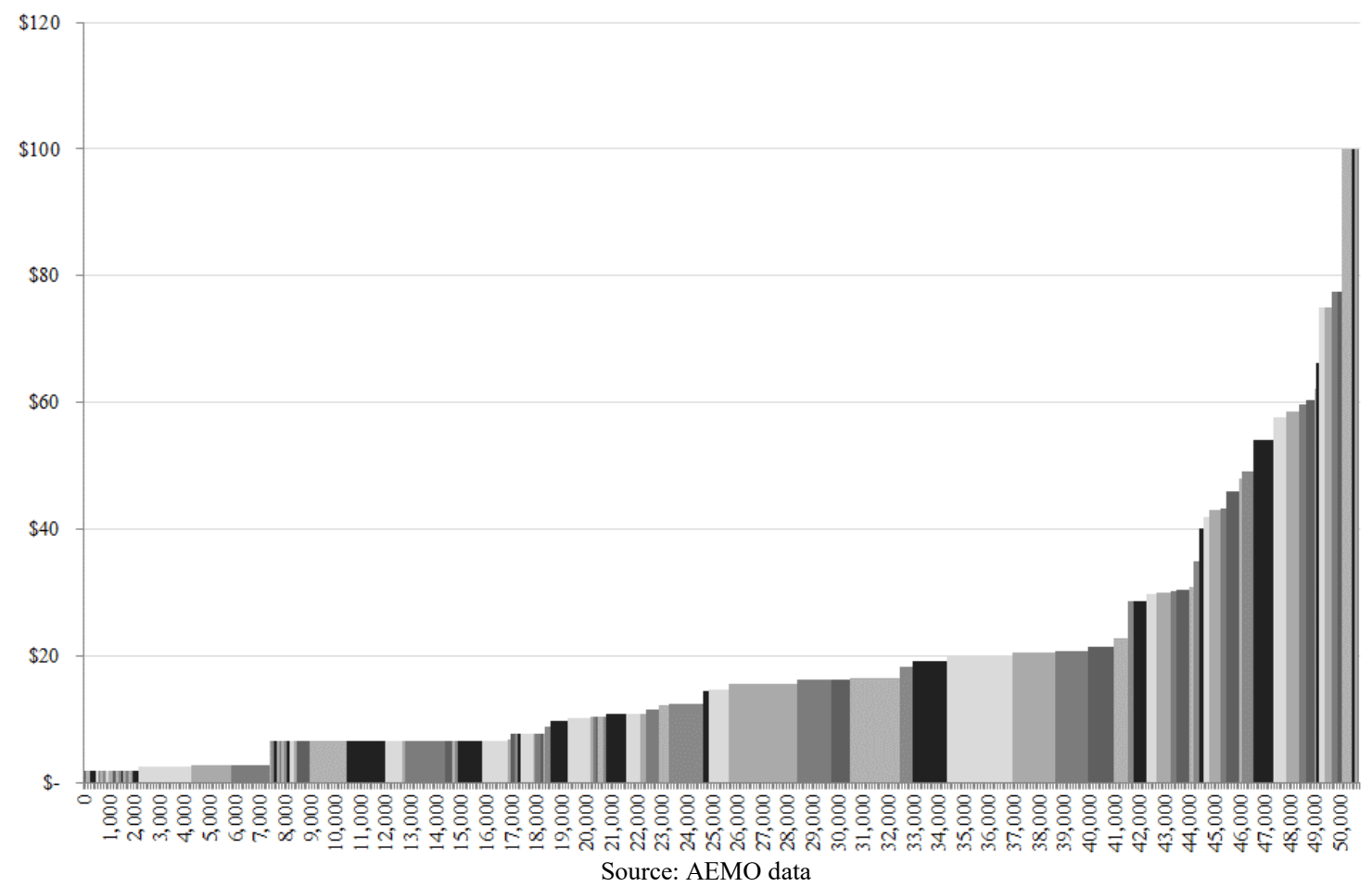


To be sure, wholesale market conditions highlighted in this article are not just problematic for investment in new renewable capacity. Thermal generators will trim maintenance capital expenditure given low electricity prices. Forced outage rates will rise. This has no short-run implications for policy makers. But it does present a long-run dilemma. Given the sunk-cost nature of existing power generation infrastructure, the intuitively logical short-run policy option is to 'do nothing' and let existing assets continue to meet demand until they fail. At such a point, prices would increase prompting new investment. However, reduced maintenance investment and mothballing plant makes the aggregate supply function inherently more uncertain. Given rising forced outage rates, a rapidly ageing capital stock and the slow (and unpredictable) speed of recalling mothballed capacity, reliability of supply events will become harder to predict. Prices will become more volatile, with long 'bust' periods followed by sudden 'spikes'. Add to this the compressed investment timeframes for requisite conventional replacement capacity if disorderly (rather than orderly) exit from the market occurs, and one can see how, in a practical sense, this is unlikely to be acceptable to policy makers who are accountable for security of energy supply in the long-run.

Barriers to exit and potential long-run risks to system reliability requires consideration by policy makers in its own right - irrespective of the intractability of new investment in renewables. It is beyond the scope of this paper to determine the quantity of plant which should ideally be retired and how and when it would be replaced. The Australian Energy Market Operator (AEMO) would be well placed to consider these issues and could be tasked by policy makers to report back on ageing infrastructure, demand having declined, significant policy induced short-run oversupply and low and increasingly unresponsive wholesale prices. At the very least policy makers may consider whether the energy-only market design is suitable for a RET and for incentivising timely and efficient replacement of the capital stock, whenever this may be required into the future ${ }^{9}$.

\section{Intractability of new investment in renewable energy under existing policy settings}

The collective impact of recent declines in demand, a sub-optimal plant mix, barriers to exit and large volumes of policy-induced renewable and low-emission energy capacity being added to the aggregate supply function has been to reduce wholesale electricity prices. At the time of writing, forward 2015 calendar (CAL15) contract prices for NSW and VIC were \$37/MWh and \$32/MWh respectively (see Appendix 1 for pricing charts for all NEM regions for CAL15 and CAL16). Traded prices have been on a general downward trajectory as market participants factor-in the convergence of the dampening variables outlined above. However, it is important to note that this trajectory has been exacerbated in 2014 by two factors that will reverse: hydro plant operating at higher output levels to take advantage of embedded carbon pricing prior to the carbon tax being removed in July; and gas-fired generation rates being higher than expected due to delays in Queensland LNG projects which have caused a short-term oversupply in the gas market.

\footnotetext{
${ }^{9}$ As an example of why such a review is necessary, ACIL Allen's modelling for the Commonwealth Government RET review forecast wholesale electricity prices to 2040 and found that prices did not exceed $\$ 50 / \mathrm{MWh}$ at any point in its 'reference' case (see page 27 of https://retreview.dpmc.gov.au/sites/default/files/papers/preliminary_modelling_results_workshop.pdf). Figure 9 in this article shows that even the cheapest generation technology requires average prices well above $\$ 50$ to be commercially viable. By inference, the ACIL Allen modelling is stating that no replacement of the existing capital stock occurs to 2040. In such a scenario, ca. $20 \%$ of the NEM's plant would be close to 70 years old in 2040. To be clear, we do not question the accuracy of the ACIL Allen modelling - we are simply making the observation that observed experience and forecast prices do not justify investments in new capacity to replace the existing capital stock.
} 
LGC prices reflect an 'expectation' that the RET policy will be amended. Renewable generators with existing (or looming) market exposures due to PPA contract maturities will invariably face substantial economic losses. With wholesale pricing of \$32-\$37/MWh and LGC revenue of $\$ 25 / \mathrm{MWh}$, total revenue accruing to renewable generators would be ca. $\$ 60 / \mathrm{MWh}-$ well below historic benchmarks needed for renewable participants to recover total average costs.

Theoretically, LGC prices can increase to $\$ 92$ per certificate (tax-effective). However we think it is unlikely to be an acceptable option for wholesale prices to decline while LGC prices increase towards the penalty level without political intervention. Such an outcome would also be unacceptable to principal investors and underwriters as the increasing proportion of LGC revenue required for a new renewable investment is created through a policy instrument that has been the subject of intense historical policy change. Without a material recovery in both the underlying electricity price and LGC prices, there is, in our opinion, a genuine risk that investment in new renewable capacity will not be forthcoming.

Some commentators have indicated that retailers are exercising market power by not writing contracts (i.e. a form of 'hold up' risk). The analysis in this article indicates that renewables are not economic, and so retailers not writing PPAs is perfectly rational behaviour particularly given prevailing uncertainty in relation to policy and the intractability of new renewable investments. If the projects were "truly economic" - retailer PPAs would not be required in the first instance. International evidence points to the impact of wholesale markets playing all but a secondary role to Power Purchase Agreements in the financing of new generation. ${ }^{10}$ On the other hand, retailers cannot make uneconomic decisions by financing projects through writing PPAs where the subsequent revenues do not recover the direct costs of the PPA. Further research should be conducted on whether tradeable renewable certificate markets play a secondary role to PPAs in the financing of new renewable generation. Such analysis may perhaps demonstrate that tradeable renewable certificate markets (like wholesale energy-only electricity markets) produce 'market' pricing that prevents the recovery of efficient costs - an extension of the 'missing money' problem.

\section{Policy implications}

Regardless of policy, greater volumes of renewables will continue to be added to Australia's energy system. The average embedded solar PV system size per installation grew by $0.9 \mathrm{~kW}$ to $3.9 \mathrm{~kW}$ in 2013 alone (esaa, 2014). Households and businesses continue to install embedded generation at rates estimated to be around 50-60 MW per month. This is despite the explicit subsidies that were once in place largely having been abandoned. Furthermore, Australia's continued deployment of renewable energy policy to incentivise large scale renewables appears to be in step with other nations. As an example, in the EU in 2012, 70\% of new generation capacity installed was renewable (REN21, 2013).

Policy should guide investors towards an economically efficient generation mix. Current policy is anything but the case. If aged plants continue to operate in a suboptimal manner with reduced operating duties and diminished revenues, they will be forced to reduce maintenance spending, forced outage rates will increase and over time security of supply will become less certain. The public policy debate in Australia therefore needs to consider two issues which are interrelated: what mechanisms could be used to drive an optimal plant mix; and how should a RET policy be structured.

\footnotetext{
${ }^{10}$ A study of 98 power generation projects built in 2011 (representing 65\% of total US capacity installed) by Caplan (2012, p.55) found that, "the construction of new power plants necessitates stable long-term financial arrangements. Long-term contracts and vertically integrated utility ownership of generation are the predominant means of supporting new capacity, especially for lower emission (plant)'.
} 
If the immediate goal being pursued by policy makers is to remove the intractability of new renewable investment, one potential option would be a material increase in the LGC penalty price. In our view this would not be supported by investors because it merely exacerbates the key problems identified in Section 5. Alternatively, policy makers may wish to shift the RET policy from a market-based mechanism to a Feed-in Tariff (FiT) arrangement to remove one component of the policy uncertainty plaguing participants. Woodman and Mitchell (2011, p. 3920), in assessing the UK Renewables Obligation (RO) concluded that a FiT may be preferable to a market-based mechanism as, 'suppliers are obliged to buy all the output from a project, so removing volume and market risk.' However, such policy responses are difficult to structure from a spatial perspective and suffer from information asymmetry. Such discussion about optimal renewable policy ignores the possibility of anticipated (i.e. subsequent) policy change, and, the underlying risks to reliability and market operation created by a persistent and sub-optimal plant mix.

It is our view that the NEM's energy-only market design requires rethinking. If institutional changes were considered appropriate, it would take a significant amount of time to implement. In the interim, correcting for barriers to exit in the context of creating a sustainable market for new renewable investment could be achieved. We consider three broad types of policy: (1) government funding of closure of aged steam plant; (2) a market-based solution; and (3) direct regulation. Importantly, solving this public policy issue requires one (or a combination) of three stakeholder groups to incur costs: governments (and by extension, taxpayers); electricity consumers; and/or incumbent thermal generators. Immediate beneficiaries would be created including all remaining generators (i.e. both conventional and renewable) and it is important to note that the costs would be incurred immediately, while the benefits to consumers and renewable investors (through greater investment in renewable generation and an orderly replacement of the existing thermal capital stock) would accrue slowly over time ${ }^{11}$.

Australia is not the only country in the world to be considering these issues. Caplan (2014, p. 33) discusses four market constructs aimed at overcoming the 'reliability challenges that are not adequately addressed by restructured wholesale electricity markets'. According to Caplan (2014, p.33), these challenges stem from, 'retirements of coal-fired generation plants, increasing levels of variable renewable resources, the need for flexible ramping capability, and increasing pressures on natural gas supplies and deliverability.' In addition to the suggestions put forward in this article, policy-makers should also consider the options articulated by Caplan (2014) with a focus on pricing the reliability value of reduced operating hours associated with generating units being made available for ramping purposes as renewable output oscillates.

It is important to note that the provision of financial incentives for permanent retirement needs to be carefully considered. Riesz, Noone and MacGill (2013, p. ii) make the salient observation that 'Payments for closure may create a vicious cycle that exacerbates barriers to exit'. However, Riesz et al (2013, p. 16) also find that in the context of achieving an optimal plant mix and encouraging further low-emission investment, 'it may be appropriate for the Government to assist incumbents in paying a proportion of these (remediation) costs'. Ultimately, to ensure an economically efficient outcome, the objective of any public policy aimed at facilitating orderly exit needs to be clear: the orderly retirement of plant that enhances reliability while facilitating a transition to lower emission electricity generation.

\subsection{Government funding of plant closure}

Governments may consider paying existing generators to permanently close existing steam plant to reduce the proportion of ageing plant capacity within the aggregate supply function. Done well,

${ }^{11}$ One reviewer observed, the long-run problem to be solved is large, but the short-run 'pain' associated with the long-run solution looks just as large! 
this would allow for re-investment in new, more economically optimal peaking plant and renewables. An auction process could be established utilising the Direct Action policy framework of the Commonwealth Government. Policy makers could either pay generators to close utilising an upfront payment to cover the costs of site-remediation or ongoing payments over several years to reflect foregone revenue, or a combination of both.

\subsection{Market-based solution}

A hitherto unexplored option within the Australian literature relates to the use of a market-based mechanism to fund permanent generator withdrawal. At present, most ageing steam plant are either running on reduced operating duties or are mothballed. In either circumstance, forward prices are adversely impacted because their potential operation places downward pressure on future prices, irrespective of whether they run. In effect, this is likely to be the first stage of disorderly withdrawal.

An alternative may be to introduce a requirement for liable entities to contract for permanent generation capacity withdrawal ${ }^{12}$. Theoretically, incumbent thermal generators should be indifferent to operating their power station and closing, if a revenue stream is provided which equals the difference between their individual short-run marginal cost and the expected average wholesale energy price. In theory, such a revenue stream may be preferred by shareholders as it eliminates operational risk associated with unexpected outages and energy portfolio management risk. A major advantage of such an approach would be that it could align the tenor of renewable energy PPAs with the tenor of withdrawal funding. This would overcome the inter-temporal issues associated with disorderly withdrawal, and facilitate an orderly and efficient exit.

However, this would increase consumer prices in two ways. First, electricity retailers would be required to pay generators to close which would raise retail prices. Second, all things being equal, the removal of plant would increase wholesale prices, at least partially, to solve the problem of the intractability of renewable energy investment articulated in this article. An estimate of the cost of closure per MWh of delivered reduction in energy ${ }^{13}$ is provided in Figure 14. The bar series (LHS) shows the incremental price at which a generator would be indifferent to being paid not to operate. The line series (RHS) shows the incremental costs to consumers (assuming that costs are spread across the entire customer load).

Figure 14 shows that the initial cost of permanently closing power stations is minor $(<\$ 5 / \mathrm{MWh})$ because a number of plants currently available for dispatch in the NEM have higher short-run marginal costs. Closure beyond 10,000 MW of plant would result in costs escalating rapidly although to be sure the size of the problem we envisage is below 10,000 MW.

\footnotetext{
12 In practice, the National Greenhouse and Energy Reporting (NGER) system could be used to determine reductions in output from existing generators which would be eligible for retailers to 'purchase' in the form of certificates representing generation reductions. Further detailed work would need to be done on how such a scheme may work in practice. In particular, policy makers would need to consider the treatment of already mothballed power stations which are currently not producing any energy.

${ }^{13}$ Calculations based upon the principle that a generator is indifferent between operating their power station and closing, if a revenue stream is provided which equals the difference between their individual short-run marginal cost and the expected average wholesale energy price.
} 
Figure 14: Market based solution costs

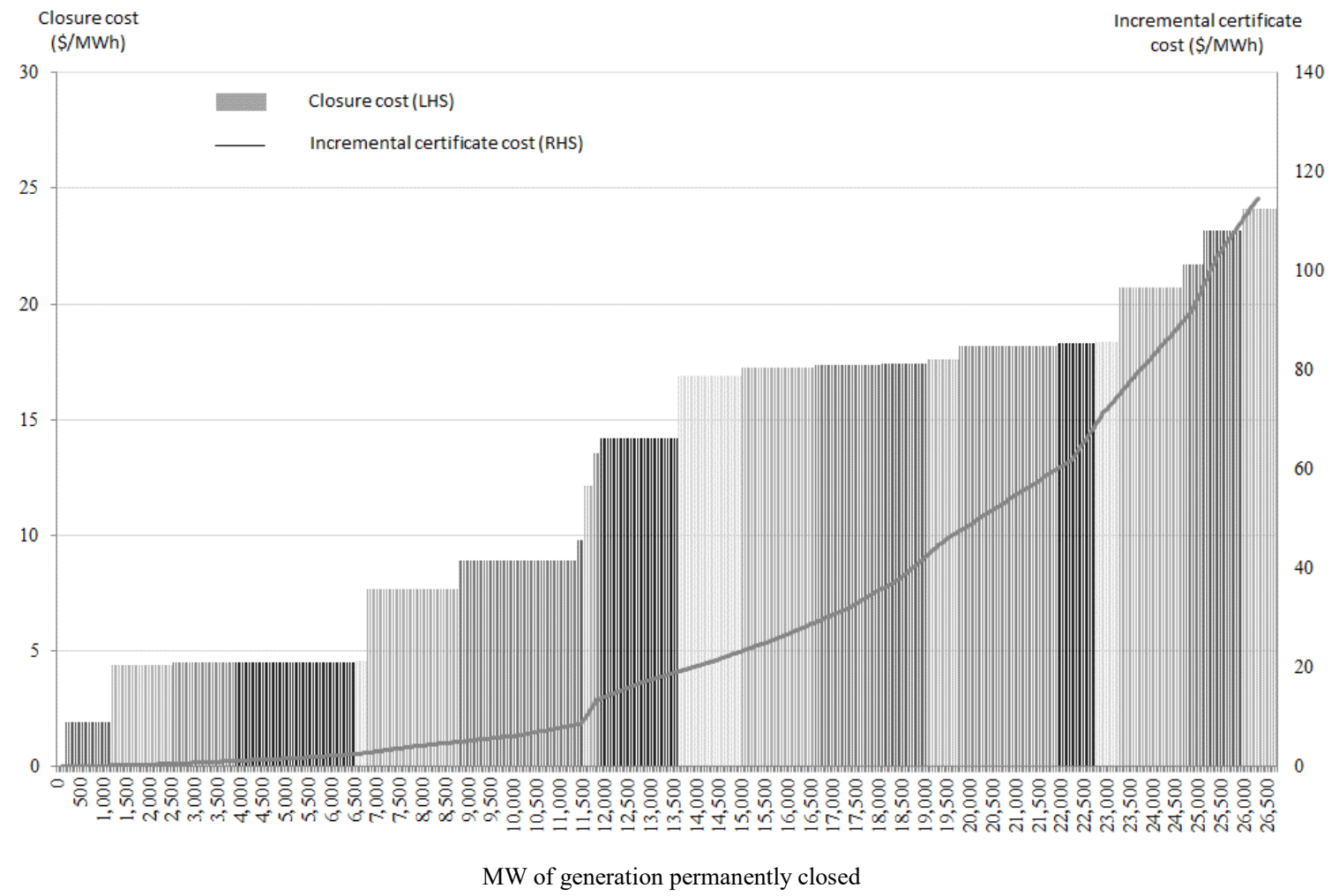

Source: Adapted from AEMO data

\subsection{Direct regulation}

A third option for removing aged plant from the market would be to introduce regulations limiting plant age such as those that exist in Europe. The Large Combustion Plant Directive (LCPD) requires individual member states of the European Union to establish restrictions on the operation of combustion plant with registered capacity greater than $50 \mathrm{MW}$. By some estimates, up to $95,000 \mathrm{MW}$ of plant could be permanently removed from European power markets as a result of LCPD over the next decade (see for example Citi Research, 2013). However, such regulation needs to be suitably telegraphed - Simshauser and Nelson (2012) demonstrate that under regulatory shock conditions, such action would contribute to investor anxiety and increase risk premiums applicable to new and refinanced plant accordingly.

\section{Conclusion}

Policy makers are about to make an explicit decision about the desirable proportion of renewable energy within its electricity system. Policy was originally set with an expectation that new electricity demand would be met by new renewable energy capacity. Demand has declined and is not expected to increase significantly in the immediate future. Given how the RET was structured (i.e. as a fixed energy target expressed in $\mathrm{MWh}$ ) further development of renewable plant capacity will increase Australia's renewable energy production beyond 20\%. Much of the public debate in Australia relates to whether the RET will achieve $20 \%$ or higher. But this focuses on the wrong issue. It is indeed puzzling why $20 \%$ has been chosen as the end goal given the lack of any scientific basis for its adoption ${ }^{14}$. What is important is the longer term trend - that is towards

\footnotetext{
${ }^{14}$ A February 2014 poll found that $64 \%$ of Australians believe the existing $20 \%$ RET is either 'too low' or 'about right'. $23 \%$ 'don't know' about the target and $13 \%$ believe it is 'too high'. See http://essentialvision.com.au/renewable-energy-target-2, Accessed March 2014.
} 
greater renewable investment at efficient costs. Policy makers should address the need to incentivise investment in an optimal plant mix while accommodating new renewable energy production and avoiding conditions that facilitate excess or inefficient capital market risk premiums.

This article has shown that investment in an optimal plant mix and associated ongoing reliability is likely to be problematic in the NEM in the long-run. This is because demand has been contracting while new renewables continue to be added to the aggregate supply function which is exacerbating an already oversupplied market. Aged incumbent steam plant continues to be available for dispatch or mothballed rather than permanently retired. Given demand forecasts are being continually revised down, closure of existing plant seems to be a crucially important step for overcoming the intractability of new renewable investment. It may very well be that the Australian community believes this is a policy goal worth pursuing in its own right given that failure to address this issue may compromise electricity system reliability and the plant retired is likely to be higher greenhouse emitting, older coal plant.

Adjusting to a new energy supply mix is not unique to Australia. The International Energy Agency (IEA) is forecasting that the global share of non-hydro renewable energy as a proportion of total power generation will double from $4 \%$ today to around $8 \%$ by 2018 (Sioshansi, 2013). In commenting on European utilities, Citi (2013, p.7) stated that: "..the operating and regulatory environment in which the utilities industry is called to operate is becoming increasingly and concurrently unpredictable and restrictive as governments' energy policy goals progress and shift'.

The policy options suggested in this article require careful consideration. In our view, achievement of the RET (at any meaningful level) appears impossible without at least one of our policy recommendations being implemented. It is important that policy intent is articulated clearly with long-term credible targets, both binding and aspirational, put in place to guide longterm investment decision making. 


\section{References}

Australian Energy Market Operator: AEMO. (2014), 2014 Planning and Forecasting Scenarios, AEMO Publication, Melbourne.

Berrie, T. (1967), 'The Economics of System Planning in Bulk Electricity Supply', Electrical Review, 22 September 1967, pp. 425-468.

Besser, J., Farr, J. and Tierney, S. (2002), 'The political economy of long-term generation adequacy: Why an ICAP mechanism is needed as part of standard market design', The Electricity Journal, Vol. 15, pp. 53-62.

Bidwell, M. and Henney, A. (2004), 'Will NETA ensure generation adequacy?', Power UK, No. 122, April.

Bushnell, J. (2010), 'Building blocks: Investment in renewable and non-renewable technologies', Energy Institute at Haas Working Paper, No. 202, Berkeley, California.

Caplan, E. (2014), 'Supplementing competition: direct payment constructs within restructured markets', The Electricity Journal, Vol. 27, No. 1, pp. 33-41.

Caplan, E. (2012), 'What drives new generation construction? An analysis of the financial arrangements behind new electric generation projects in 2011', The Electricity Journal, Vol. 25, No. 6, pp. 48-61.

Citi Research, (2013), 'Pan-European Utilities: The Lost Decade, Where Next', Citi Research Equities Note, 17 June 2013.

Climate Change Authority: CCA. (2012), Renewable Energy Target Review, CCA Publication, Melbourne.

Commonwealth Government. (2011), Contract for Closure: Program Administrative Guidelines, Commonwealth Government Publication, Canberra, 30 September 2011.

The Community of Practice for Coal Utilisation: CPCU. (2014), "2014 Plant Database", The Community of Practice for Coal Utilisation, Brisbane.

Cramton P. and Stoft, S. (2006), "The convergence of market designs for adequate generating capacity with special attention to the CAISOs resource adequacy problem", Cambridge, MA: Center for Energy and Environmental Policy Research.

de Vries, L. (2003), "The instability of energy-only electricity markets", Research Symposium: European Electricity Markets, The Hague, September 2003.

de Vries, L. (2004), "Securing the public interest in electricity generation markets, the myths of the invisible hand and the copper plate", PhD Dissertation, Delft University of Technology, The Netherlands.

de Vries, L. And Heijnen, P. (2008), "The impact of electricity market design upon investment under uncertainty: the effectiveness of capacity mechanisms", Utilities Policy, Vol.16, pp. 215227. 
Department of Industry, Innovation, Climate Change, Science, Research and Tertiary Education: DIICCSRTE. (2013), Quarterly Update of Australia's National Greenhouse Gas Inventory December Quarter 2012, Canberra.

Edenhofer, O., Hirth, L., Knopf, B., Pahle, M., Schlömer, S., Schmid, E., and Ueckerdt, F. (2013), 'On the economics of renewable energy sources', Energy Economics, Vol. 40, Supplement 1, pp. S12-S23.

Energy Supply Association of Australia: esaa. (2014), ESAA Solar Report January 2014, esaa Publication, Melbourne.

Energy Supply Association of Australia: esaa. (2013), Electricity Gas Australia 2013, esaa Publication, Melbourne.

Felder, F. (2011), 'Examining electricity price suppression due to renewable resources and other grid investments', The Electricity Journal, Vol. 24, No. 4, pp. 34-46.

Finon, D. (2008), "Investment risk allocation in decentralised markets: the need of long-term contracts and vertical integration", OPEC Energy Review, Vol.32, No.2, pp. 150-183.

Finon, D. and Pignon, V. (2008), "Electricity and long-term capacity adequacy: the quest for regulatory mechanisms compatible with electricity markets", Utilities Policy, Vol.16, pp.143-158.

Joskow, P. (2006), "Competitive electricity markets and investment in new generating capacity", AEI-Brookings Joint Centre for Regulatory Studies, Working Paper No.06-14.

Joskow, P. (2008b), "Capacity payments in imperfect electricity markets: need and design", Utilities Policy, Vol.16, pp. 159-170.

Lewis, M. (2014), Europe's Electric Shock: Lessons for Australia, Report for the Energy Supply Association of Australia: esaa, Melbourne.

McConnell, D., Hearps, P., Eales D., Sandiford, M., Dunn, R., Wright, M. and Bateman, L. (2013), " Retrospective modelling of the merit-order effect on wholesale electricity prices from distributed photovoltaic generation in the Australian National Electricity Market', Energy Policy, Vol. 58, pp. 17-27.

Molyneaux, L., Froome, C., Wagner, L., and Foster, J. (2013), “Australian power: Can renewable technologies change the dominant industry view?”, Renewable Energy, Vol. 60, pp. 215-221.

Nelson, T., McNeill, J., and Simshauser, P. (2014), 'From throughput to access fees: The future of network and retail tariffs' in Sioshansi, F. (ed), Distributed Generation and its Implications for the Utility Industry.

Nelson, J. and Simshauser, P. (2013), 'Is the Merchant Power Producer a broken model', Energy Policy, Vol. 53(C), pp. 298-310.

Nelson, T., Nelson, J., Ariyaratnam, J., and Camroux, S. (2013), 'An analysis of Australia's large scale renewable energy target: Restoring market confidence,' Energy Policy, Vol. 62(C), pp. 386400. 
Nelson, T., Simshauser, P., and Nelson, J. (2012), 'Queensland solar feed-in tariffs and the meritorder effect: economic benefit, or regressive taxation and wealth transfers?', Economic Analysis and Policy (EAP), Vol. 42, No. 3, pp. 277-301.

Nelson, T., Kelley, S., Orton, F., and Simshauser, P. (2011), 'Delayed Carbon Policy Certainty and Electricity Prices in Australia: A Concise Summary of Subsequent Research', Economic Papers, Vol. 31, No. 1, pp. 132-135.

Nelson, T., Kelley, S., Orton, F., and Simshauser, P. (2010), 'Delayed Carbon Policy Certainty and Electricity Prices in Australia', Economic Papers, Vol. 29, No. 4, pp. 446-465.

Neuhoff, K. and De Vries, L. (2004), "Insufficient incentives for investment in electricity generation", CMI Working Paper 42, Cambridge.

Newbery, D. (2006), “Market Design”, EPRG Working Paper No. 0515, University of Cambridge. Available at http://www.eprg.group.cam.ac.uk/category/publications/working-paperseries.

Oren, S. (2003), "Ensuring generation adequacy in competitive electricity markets", University of California Energy Institute - Energy Policy \& Economics 007, University of California, Berkley.

Peluchon, B. (2003), "Is investment in peak generation assets efficient in a deregulated electricity sector?", Research Symposium: European Electricity Markets, The Hague, September 2003.

Renewable Energy Policy Network for the $21^{\text {st }}$ Century: REN21. (2013), Renewables 2013 Global Status Report, REN21 Publication, Paris.

Riesz, J. (2014), 'Will the NEM energy-only market work with high renewables?', CSIRO FutureGrid Conference Presentation, February.

Riesz, J., Noone, B., and MacGill, I. (2013), 'Payments for Closure: Should Direct Action include payments for closure of high emission coal-fired power plants?', CEEM Working Paper.

Roques, F., Newbery, D. and Nuttall, W. (2005), "Investment incentives and electricity market design: the British experience", Review of Network Economics, Vol.4, No.2, pp. 93-127.

Sensfuß, F., Ragwitz, M., Genoese, M. (2008), 'The merit-order effect: A detailed analysis of the price effect of renewable electricity generation on spot market prices in Germany', Energy Policy, Vol. 36, No. 8, pp. 3086-3094.

Saddler, H. (2013), 'Power Down: Why is electricity consumption decreasing', Australia Institute Paper, No. 14.

Schweppe, F., Caramanis, M., Tabors, R. And Bohn, R. (1988), Spot pricing of electricity, Kluwer Academic Publishers, London.

Simshauser, P., and Ariyaratnam, J. (2014), 'What is Normal Profit for power generation?', Journal of Financial Economic Policy, Vol. 6, No. 2.

Simshauser, P., and Nelson, T. (2014), 'Solving for X: The NSW Gas Supply Cliff', AGL Applied Economic Policy and Research Working Paper Series, No. 40. 
Simshauser, P. and Nelson, T. (2013), 'The Outlook for Residential Electricity Prices in Australia's National Electricity Market in 2020', The Electricity Journal, Vol. 26, No. 4, pp. 6683.

Simshauser, P and Nelson, T. (2012), 'The second-round effects of carbon taxes on power project finance,' Journal of Financial Economic Policy, Vol. 4, No. 2, pp. 104-127.

Simshauser, P., Nelson, T., and Doan, T. (2011), 'The boomerang paradox, part II: policy prescriptions for reducing fuel poverty in Australia', The Electricity Journal, Vol. 24, No. 2, pp. 63-75.

Simshauser, P. (2014), 'The cost of capital for power generation in atypical capital market conditions', Economic Analysis and Policy, Vol. 44, No. 2, pp. 184-201.

Simshauser, P. (2010), 'Vertical integration, credit ratings and retail price settings in energy-only markets: Navigating the Resource Adequacy problem,' Energy Policy, Vol. 38, No. 11, pp. 7427 7441.

Simshauser, P. (2009), "On emissions trading, toxic debt, and the Australian power market", Electricity Journal, Vol.22, No.2, pp. 9-29.

Simshauser, P. (2008), 'The Dynamic Efficiency Gains from Introducing Capacity Payments in the National Electricity Market', The Australian Economic Review, Vol. 41, No. 4, pp. 349-70.

Simshauser, P. (2006), 'The Emergence of Structural Faults on the Supply Side in Deregulated 'Energy Only' Electricity Markets,' Australian Economic Review, Vol. 39, No. 2, pp 130-146.

Simshauser, P. (2001), 'Excess Entry in the Deregulated Queensland Power Market,' Economic Analysis and Policy (EAP), Vol. 31, No. 1, pp. 73-92.

Sioshansi, F. (2013), EEnergy Informer: The International Energy Newsletter, Vol.23, No.8, August.

Wilkins, R. (2008), Strategic Review of Australian Government Climate Change Programs, Commonwealth Government Publication, Canberra.

Wen, F., Wu, F. and Ni, Y. (2004), "Generation capacity adequacy in the competitive electricity market environment”, Electrical Power \& Energy Systems, Vol.26, pp. 365-372.

Woodman, B., and Mitchell, C. (2011), 'Learning from experience? The development of the Renewables Obligation in England and Wales 2002-2010', Energy Policy, Vol. 39, pp. 39143921 . 


\section{Appendix 1: CAL15 and CAL16 forward electricity prices}

\section{Figure 15: CAL15 Contract Pricing}

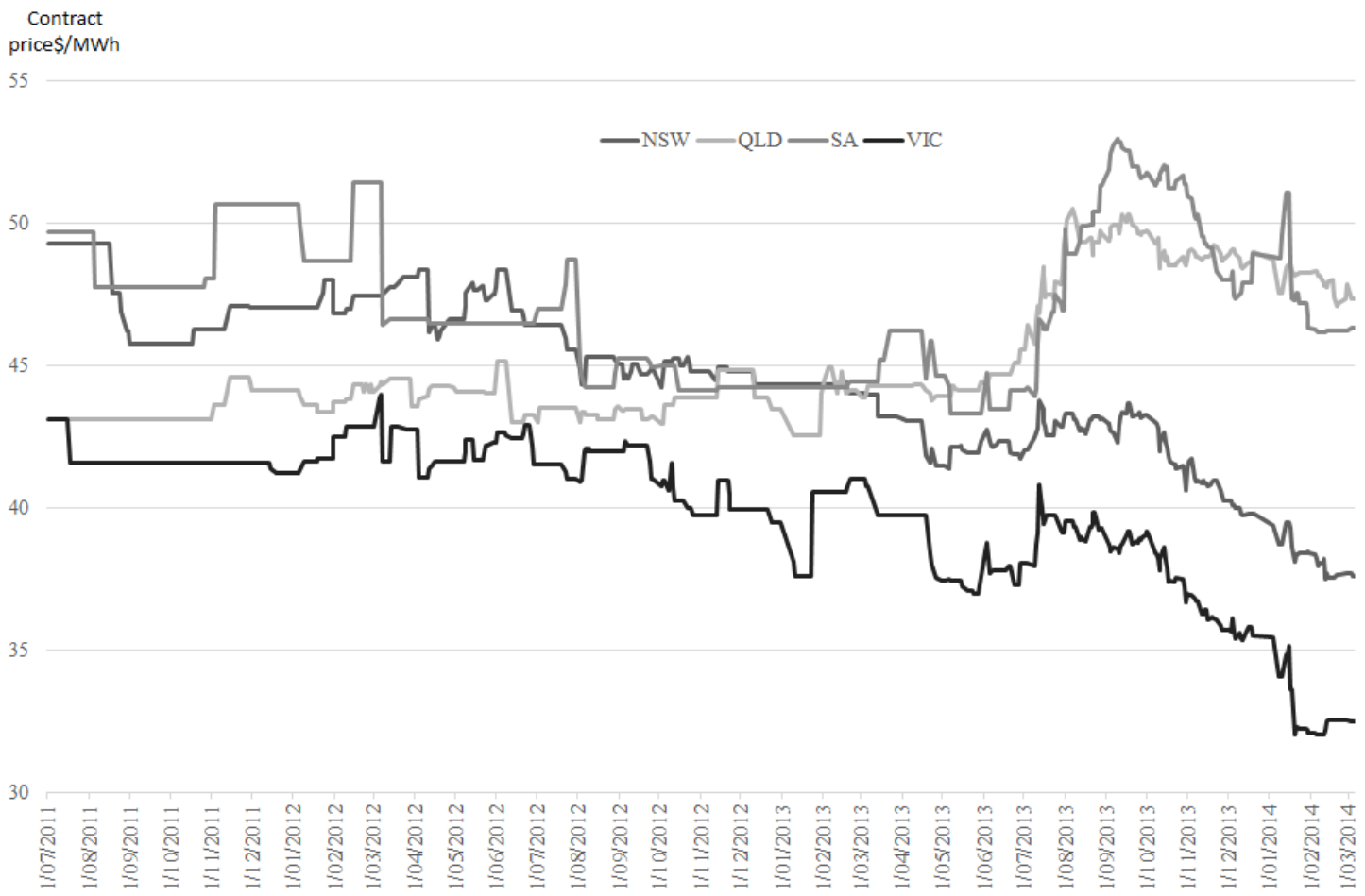

Figure 16: CAL16 Contract Pricing

Contract

price\$/MWh

60

$$
-\mathrm{NSW}-\mathrm{QLD}-\mathrm{SA}-\mathrm{VIC}
$$
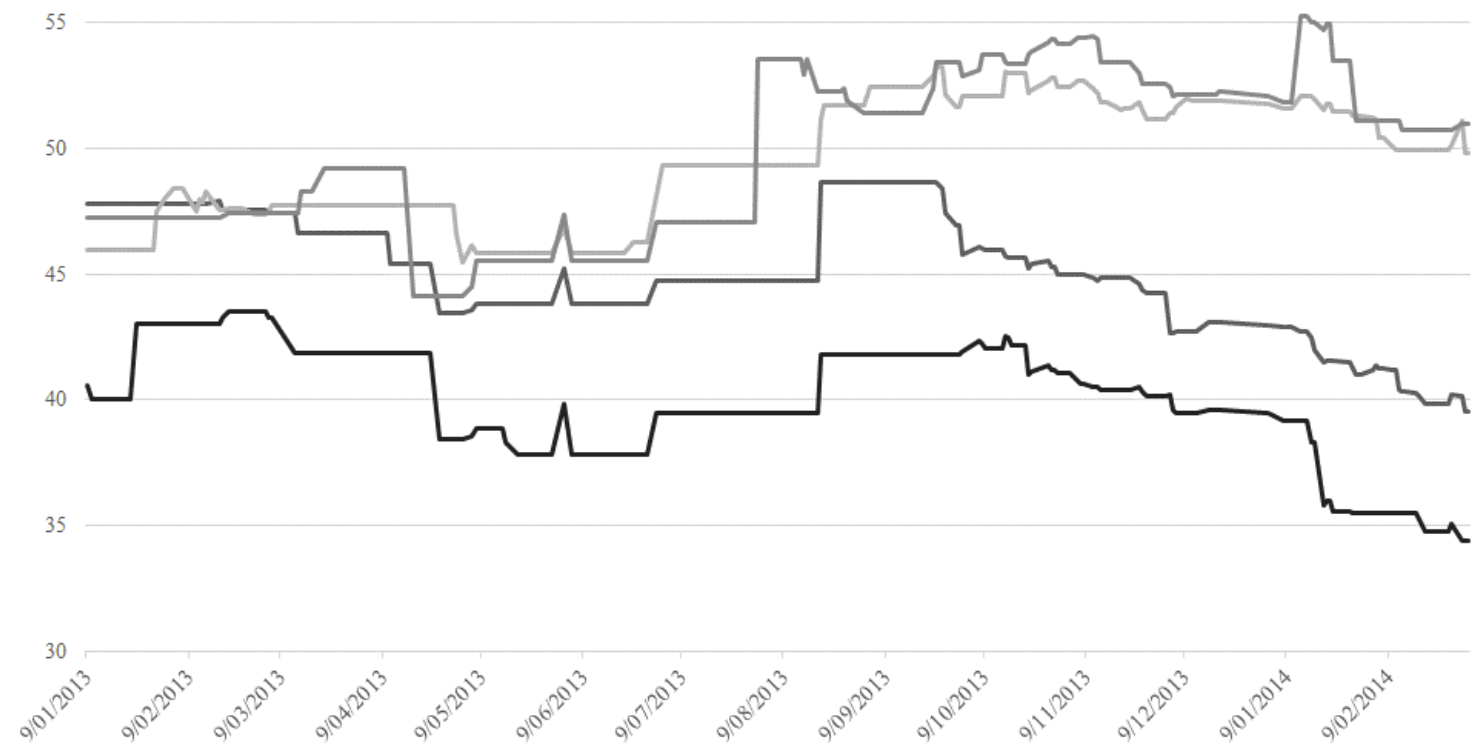


\section{Declaration by the authors}

Two of the authors of this working paper are employed by AGL Energy Ltd. While the working paper represents the views of the authors, the research was undertaken to inform AGL Energy's public position in relation to electricity market development and reform.

Earlier drafts of the paper were reviewed by the AGL Applied Economic and Policy Research Council and comments made by Council members were gratefully received by the authors. The role of the Council is not to endorse working papers but provide constructive review. All opinions, statements, errors and omissions are those of the authors and should not in any way be attributed to the Council and its members. Members of the Council are Elizabeth Nosworthy, the Hon. Patrick Conlon, Prof. Christine Smith, Prof. Stephen Gray, Keith Orchison, Tony Brinker and Carlo Botto. 